\title{
Molecular Dissection of the Interaction between the AMPA Receptor and Cornichon Homolog-3
}

\author{
Natalie F. Shanks, ${ }^{1,3,4}$ Ondrej Cais, ${ }^{6}$ Tomohiko Maruo, ${ }^{3}$ 'Deffrey N. Savas, ${ }^{5}$ Elena I. Zaika, ${ }^{1}$ Caleigh M. Azumaya, ${ }^{1}$ \\ John R. Yates III, ${ }^{5}$ Ingo Greger, ${ }^{6}$ and Terunaga Nakagawa ${ }^{1,2,3}$ \\ ${ }^{1}$ Department of Molecular Physiology and Biophysics and ${ }^{2}$ Center for Structural Biology, Vanderbilt University, School of Medicine, Nashville, Tennessee \\ 37232, ${ }^{3}$ Department of Chemistry and Biochemistry and ${ }^{4}$ Neurosciences Graduate Programs, University of California, San Diego, La Jolla, California 92093, \\ ${ }^{5}$ Department of Chemical Physiology, The Scripps Research Institute, La Jolla, California 92037, and ${ }^{6}$ Medical Research Council Laboratory of Molecular \\ Biology, CB2 0QH, Cambridge, United Kingdom
}

Cornichon homologs (CNIHs) are AMPA-type glutamate receptor (AMPAR) auxiliary subunits that modulate AMPAR ion channel function and trafficking. Mechanisms underlying this interaction and functional modulation of the receptor complex are currently unclear. Here, using proteins expressed from mouse and rat cDNA, we show that CNIH-3 forms a stable complex with tetrameric AMPARs and contributes to the transmembrane density in single-particle electron microscopy structures. Peptide array-based screening and in vitro mutagenesis identified two clusters of conserved membrane-proximal residues in CNIHs that contribute to AMPAR binding. Because CNIH-1 binds to AMPARs but modulates gating at a significantly lower magnitude compared with CNIH-3, these conserved residues mediate a direct interaction between AMPARs and CNIHs. In addition, residues in the extracellular loop of CNIH-2/3 absent in CNIH-1/4 are critical for both AMPAR interaction and gating modulation. On the AMPAR extracellular domains, the ligand-binding domain and possibly a stretch of linker, connecting the ligand-binding domain to the fourth membrane-spanning segment, is the principal contact point with the CNIH-3 extracellular loop. In contrast, the membrane-distal N-terminal domain is less involved in AMPAR gating modulation by CNIH-3 and AMPAR binding to CNIH-3. Collectively, our results identify conserved residues in the membrane-proximal region of CNIHs that contribute to AMPAR binding and an additional unique segment in the CNIH-2/3 extracellular loop required for both physical interaction and gating modulation of the AMPAR. Consistent with the dissociable properties of binding and gating modulation, we identified a mutant CNIH-3 that preserves AMPAR binding capability but has attenuated activity of gating modulation.

Key words: AMPA receptor; complex; cornichon; gating modulation; molecular mechanism; single particle EM

\section{Introduction}

Excitatory synaptic transmission mediated by the AMPA-type glutamate receptor (AMPAR) is subject to modulation by a variety of structurally diverse transmembrane (TM) proteins, such as stargazin/ transmembrane AMPA receptor regulatory proteins (TARPs), cornichon homologs (CNIHs), GSG1L, and CKAMP44

Received Feb. 11, 2014; revised July 14, 2014; accepted July 29, 2014.

Author contributions: N.F.S. and T.N. designed research; N.F.S., O.C., T.M., J.N.S., E.Z., C.M.A., I.G., and T.N. performed research; N.F.S., O.C., T.M., J.N.S., J.R.Y., I.G., and T.N. contributed unpublished reagents/analytic tools; N.F.S., O.C., J.N.S., I.G., and T.N. analyzed data; N.F.S. and T.N. wrote the paper.

We thank Osamu Chisaka (Kyoto University) for the anti-CNIH antibody and C. J. Allison and Susan Taylor [University of California, San Diego (UCSD)] for preparing the peptide array used in the initial experiments. We acknowledge the use of the UCSD Cryo-Electron Microscopy Facility, which was supported by National Institutes of Health (NIH) Grants 1S10RR20016 and GM033050 (to Dr. Timothy S. Baker) and a gift from the Agouron Institute to UCSD. N.F.S is supported by NIH Molecular Biophysics Training Grant GM08326 at UCSD. C.M.A. is supported by the NIH Molecular Biophysics Training Grant GM008320 at Vanderbilt University Medical Center. J.N.S. is supported by National Institute of Aging Fellowship F32AG039127. J.R.Y. is supported by NIH Grants R01 MH067880, P41 GM103533, and R01 HL079442. T.N. was supported by NIH Grant R01HD061543 and Vanderbilt University Medical Center.

Correspondence should be addressed to Terunaga Nakagawa, Department of Molecular Physiology and Biophysics, Center for Structural Biology, Vanderbilt University, School of Medicine, 766 Robinson Research Building, Nashville, TN 37232. E-mail: terunaga.nakagawa@vanderbilt.edu.

DOI:10.1523/JNEUROSCI.0595-14.2014

Copyright $\odot 2014$ the authors $\quad 0270-6474 / 14 / 3412104-17 \$ 15.00 / 0$
(Hashimoto et al., 1999; Chen et al., 2000; Tomita et al., 2005; Nicoll et al., 2006; Schwenk et al., 2009, 2012; Kalashnikova et al., 2010; von Engelhardt et al., 2010; Jackson and Nicoll, 2011; Shanks et al., 2012). Whereas the molecular diversity of AMPAR complexes has continued to grow (Kang et al., 2012; Schwenk et al., 2012; Shanks et al., 2012), the biochemical properties and mechanisms underlying AMPAR modulation are essentially uncharacterized for these individual complexes.

Various neurological phenotypes were observed in the absence of stargazin/TARPs (Jackson and Nicoll, 2011), whereas changes in synaptic plasticity have been reported in mutant mice lacking stargazin/TARPs (Jackson and Nicoll, 2011) and CKAMP44 (von Engelhardt et al., 2010). In addition, knock-out of $\mathrm{CNIH}-2 / 3$ in mice alters the synaptic content of GluA1containing AMPARs, resulting in a reduction in both AMPARmediated transmission and long-term potentiation (Herring et al., 2013). Manipulating CNIH-2 levels in the hippocampus alters the kinetics of synaptic AMPARs, revealing a regulatory role of CNIH-2 in AMPAR-mediated transmission (Boudkkazi et al., 2014). Similarly, in Caenorhabditis elegans, the mutations of auxiliary factors, such as sol-1, sol-2, stg-1, stg-2, and cni, result in phenotypes consistent with deficits in ion channel function of 
GLR glutamate receptors (Zheng et al., 2004; Wang et al., 2008, 2012; Brockie et al., 2013). These results indicate that endogenous factors modulating AMPARs significantly affect normal nervous system function. Exogenously introduced small molecules and recombinant proteins can potentially adopt similar molecular strategies as these endogenous factors in modulating AMPARs. Therefore, a precise understanding of these processes may contribute to developing therapeutic reagents for neurological and psychiatric disorders caused by AMPAR dysfunction.

Among the membrane proteins that modulate AMPARs, the biochemical stability of the complex has only been established for the stargazin/TARP family, distinguishing them as bona fide AMPAR auxiliary subunits (Nakagawa et al., 2005; Vandenberghe et al., 2005; Jackson and Nicoll, 2011). In this study, we combined single-particle electron microscopy (EM), a biochemical binding assay, in vitro mutagenesis, and electrophysiology to investigate the nature of CNIH/AMPAR complexes and probe the molecular mechanisms of gating modulation.

By dissecting the complex molecular associations between the two proteins, we identify an interaction between the extracellular loop of CNIH-3 and the isolated ligand-binding domain (LBD) containing a segment of the linker that connects the LBD and fourth transmembrane domain (TMD) of the GluA2 subunit. Intervening the intermolecular interactions in the LBD by cyclothiazide and/or residue-specific substitutions modulates AMPAR gating kinetics (Sun et al., 2002; Horning and Mayer, 2004). This study extends these existing models by demonstrating direct binding between the extracellular loop of CNIH-3 and the AMPAR LBD with residue-specific precision. Our results also highlight the involvement of the regions around the AMPAR TMDs in channel modulation by auxiliary subunits.

\section{Materials and Methods}

Brain tissues used in this study are derived from either sex.

\section{Recombinant DNA}

GluA2 construct. The rat GluA2 flip splice variant was used for all experiments. The FLAG tag was inserted at the C-terminal domain (FATDYKDDDDKEGYNVYGIESVKI, in which bold indicates the FLAG epitope), preserving the original anti-GluA2CT epitope. pTREt (Clontech) and pCMV were used to express this construct.

GluA2/GluK6 chimera constructs. The operations TM1-3 swap, TM1-3 + linker swap, and TM4 swap are defined as follows.

TM1-3 swap. The GluK2 TM1-3 sequence IWMYVLLACLGVSC VLFVIARFSPYEWYNPHPCNPDSDVVENNFTLLNSFWFGVGALMR QGSELMPKALSTRIVGGIWWFFTLIIISSYTANLAA was swapped for the GluA2 TM1-3 sequence IWMCIVFAYIGVSVVLFLVSRFSPYEWH TEEFEDGRETQSSESTNEFGIFNSLWFSLGAFMRQGCDISPRSLSGRI VGGVWWFFTLIIISSYTANLAA.

TM1-3 + linker swap. The GluK2 sequence PNGTNPGVFSFLNP LSPDIWMYVLLACLGVSCVLFVIARFSPYEWYNPHPCNPDSDVVEN NFTLLNSFWFGVGALMRQGSELMPKALSTRIVGGIWWFFTLIIISSYTANLAAFLTVERMESP was swapped for the GluA2 sequence PQKS KPGVFSFLDPLAYEIWMCIVFAYIGVSVVLFLVSRFSPYEWHTEEFED GRETQSSESTNEFGIFNSLWFSLGAFMRQGCDISPRSLSGRIVGGVW WFFTLIIISSYTANLAAFLTVERMVSP.

TM4 swap. The GluK2 amino acid sequence SALGVQNIGGIFIVLAAGLVLSVFVAVG was inserted into the GluA2 sequence between GSSLGNAVNLAVLKLNEQGLLDKLKNKWWYDKGECGSGGGDSKEKT and EFCYKSRAEAKRMKVAKNPQNINPSSSQNSQNFATYKEGYNVYGIESVKI.

A2-TM4K2 was made from GluA2 with TM4 swap operation. A2TMK2 was made from GluA2 with TM1-3 swap operation. A2TMK2TM4Ks was made from GluA2 by combining TM1-3 swap and TM4 swap operations. A2-LTMK2 was made from GluA2 with TM1-3 + linker swap operation. A2-LTMK2TM4K2 was made from GluA2 by combining TM1-3 + linker swap and TM4 swap operations.

GluA2 S1S2 extended linker construct. pETQG was created according to Chen et al. (1998). The S1S2 flop extended linker construct is made with S1 (SGNDTSGLEN...SIMIKK), GT linker, and S2 (PIESAE...GGGDSKEKTS, extending into pre-M4).

GluA2 N-terminal domain construct. The entire GluA2 N-terminal domain (NTD) up to the sequence GACACGTCTGGGCTTGAAAACAAG was subcloned into a pIRES-mCherry 5Glycine Thrombin His8 vector (Farina et al., 2011).

NMDAR subunit constructs. Rat GluN1-1a splice variant was subcloned into the NotI site of PTRE-A vector as described previously (Farina et al., 2011). For pTRE-B-GluN2B3xFLAG, rat GluN2B cDNA bearing 3xFLAG tag at the C-terminal domain (... PRAFNG DYKDHDGDYKDHDIDYKDDDDKSSNGHVYEKLSSIESDVstop, in which bold indicates the $3 \times$ FLAG epitope) was cloned into the pTRE-B vector between the EcoRI and EcoRV sites. pTRE-A-GluN1 and pTRE-BGluN2B3xFLAG\#1 vectors were then combined into a dual expression vector as described previously (Farina et al., 2011).

CNIH-1,2,3 constructs. Mouse CNIH cDNA clones were obtained from Open Biosystems. The HA tag was inserted at the very C terminus of CNIH-3. The CNIH-3-HA mCherry cassette was subcloned into the pBOSS vector (a gift from Shigekazu Nagata and Hideki Sakahira, Osaka University, Japan) downstream of the elongation factor promoter. To create CNIH-3 point mutants, three residues at a time were mutated to alanines using in vitro mutagenesis QuikChange protocol (Stratagene). In the CNIH-3 deletion mutant, the sequences within the extracellular loop (see Fig. 7A) were removed by PCR. CNIH-3 with a 3xFLAG tag at the $\mathrm{C}$ terminus was cloned into pTREt (Clontech) for expression.

\section{Generation of stable HEK cell lines that expresses one type of} protein by doxycycline induction

TetOnGluA2 flip (clone 4), TetOnCNIH-3 3xFLAG, and TetOnCNIH-3 HA are stable TetOnHEK cells that doxycycline (DOX) dependently expresses GluA2-FLAG, CNIH-3-3xFLAG, and CNIH-3-HA, respectively. These cell lines were created by previously described methods (Shanks et al., 2010).

Generation of stable HEK cell lines that express GluA2-FLAG by DOX induction and constitutively express $\mathrm{CNIH}-1$ or $\mathrm{CNIH}-3$ The cell line described above that DOX dependently expresses GluA2 was cotransfected with pBOSS-CNIH-3HA-IRES-mCherry and pCMVZeocin (Invitrogen) at a ratio of 25:1. Several different lines (TetOnGluA2/ CNIH-3 clones 1, 3, 5, and 9) were isolated that expressed different levels of CNIH-3. TetOnGluA2/CNIH-1 clones 1 and 10 are two clones isolated that constitutively expressed $\mathrm{CNIH}-1-\mathrm{HA}$ and DOX dependently expressed GluA2, using an identical expression strategy as TetOnGluA2/ CNIH-3.

\section{Generation of stable HEK cell lines that express GluN1} and GluN2B

The DOX inducible GluN1/GluN2B3xFLAG\#1 dual-expressing cell line was generated as follows; pTRE-GluN1/GluN2B3xFLAG\#1 dualexpressing vector was linearized by digesting with $\mathrm{ScaI}$ and cotransfected with a plasmid that expresses a hygromycin resistant gene into TetOnHEK cells. Selection of clones was done over 2 weeks in DMEM (Mediatech) containing $10 \% \mathrm{FCS}$, penicillin $(100 \mathrm{U} / \mathrm{ml}) /$ streptomycin $(100$ $\mu \mathrm{g} / \mathrm{ml}$ ) (Invitrogen), $120 \mu \mathrm{g} / \mathrm{ml} \mathrm{G} 418,120 \mu \mathrm{g} / \mathrm{ml}$ hygromycin, $1 \mathrm{~mm}$ kynurenic acid, $10 \mathrm{mM} \mathrm{MgSO}_{4}$, and $2.5 \mu \mathrm{M}(+) \mathrm{MK} 801$ (Ascent). Colonies of HEK cells that survived selection were plated and grown. A portion of each clone was cultured in 96-well format and induced in the absence of $(+)$ MK801. Cell death exhibiting clones were further expanded as candidate clones. As the final check, expression of GluN1 and GluN2B3xFLAG\#1 in the same cells was examined by Western blotting and immunocytochemistry using antibodies against the GluN1 C1 exon (rabbit polyclonal; Sheng et al., 1994) and FLAG epitope [M2 mouse monoclonal; Research Resource Identifier (RRID): AB_439685; catalog \# P2983; Sigma-Aldrich]. 
Purification of recombinant GluA2 and GluA2/CNIH-3 from HEK cells

Cell pellet was obtained from monolayer culture of $20 \times 15 \mathrm{~cm}$ plates after a $24 \mathrm{~h}$ induction with DOX. Approximately $6 \mathrm{ml}$ of cell pellet was resuspended in $50 \mathrm{ml}$ of buffer containing $50 \mathrm{~mm} \mathrm{Na-HEPES,} \mathrm{pH} \mathrm{7.4,} 85$ $\mathrm{mm} \mathrm{NaCl}, 15 \mathrm{~mm} \mathrm{KCl}, 30 \mu \mathrm{M} \mathrm{NBQX}$, and protease inhibitors (1 mM PMSF, $10 \mu \mathrm{g} / \mathrm{ml}$ leupeptin, atropinin, benzamidine, and pepstatin A). Extraction was accomplished with dodecylmaltoside (DDM) $(0.25 \%)$ at $4^{\circ} \mathrm{C}$ for $3 \mathrm{~h}$. The lysate was ultracentrifuged (Beckman $45 \mathrm{Ti}$ rotor) at $45,000 \mathrm{rpm}$ for $1 \mathrm{~h}$ at $4^{\circ} \mathrm{C}$, and the supernatant was passed through a column made of protein A Sepharose beads (GE Healthcare) crosslinked using dimethyl pimelimidate (DMP) (Pierce) to anti-FLAG M2 monoclonal antibody (RRID: AB_439685; catalog \#P2983; SigmaAldrich) at a concentration of $2 \mathrm{mg} / \mathrm{ml}$. After three washes, bound proteins were eluted using $0.5 \mathrm{mg} / \mathrm{ml}$ FLAG peptide in buffer. The peak elution sample was further separated by size using a Superdex 200 gel filtration column (GE Healthcare) in $50 \mathrm{~mm}$ Na-HEPES, pH 7.4, $85 \mathrm{~mm}$ $\mathrm{NaCl}, 15 \mathrm{~mm} \mathrm{KCl}$, and $0.1 \%$ DDM.

In vitro interaction between purified GluA2 and $\mathrm{CNIH}-3$

GluA2-FLAG and CNIH-3-3xFLAG were purified in parallel. HEK cell pellets were obtained $24 \mathrm{~h}$ after induction with DOX. Approximately $5 \mathrm{ml}$ of cell pellet was resuspended in $40 \mathrm{ml}$ of buffer containing $50 \mathrm{~mm} \mathrm{Na}$-HEPES, $\mathrm{pH}$ 7.4, $150 \mathrm{~mm} \mathrm{NaCl}$, protease inhibitors (1 mм PMSF, $10 \mu \mathrm{g} / \mathrm{ml}$ leupeptin, atropinin, benzamidine, and pepstatin A), and $30 \mu \mathrm{M}$ NBQX for GluA2. Extraction was accomplished with $0.25 \%$ DDM (supplemented with $0.1 \%$ 1-palmitoyl-2-oleoyl-sn-glycero-3-phosphocholine (POPC) to extract GluA2) at $4^{\circ} \mathrm{C}$ for $3 \mathrm{~h}$. The lysate was centrifuged at $3500 \mathrm{rpm}$ for $10 \mathrm{~min}$ at $4^{\circ} \mathrm{C}$ and then ultracentrifuged (Beckman 70.1 Ti rotor) at 50,000 rpm for $1 \mathrm{~h}$ at $4^{\circ} \mathrm{C}$.

The supernatants were incubated separately with $400 \mu \mathrm{l}$ of protein A Sepharose beads (GE Healthcare) cross-linked using DMP (Pierce) to anti-FLAG M2 monoclonal antibody (RRID: AB_439685; catalog \#P2983; Sigma-Aldrich) at a concentration of $2 \mathrm{mg} / \mathrm{ml}$ each overnight. After four washes, bound proteins were eluted using $0.5 \mathrm{mg} / \mathrm{ml}$ FLAG peptide in buffer for GluA2 and $0.2 \mathrm{mg} / \mathrm{ml} 3 x$ FLAG peptide in buffer for CNIH-3. The second elution fractions ( $500 \mu \mathrm{l}$ total volume) were used in the following. One hundred sixty microliters of both GluA2 and CNIH-3 were mixed and incubated for $1 \mathrm{~h}$ at $4^{\circ} \mathrm{C}$. Three tubes of protein $\mathrm{A}$ Sepharose beads (GE Healthcare) cross-linked using DMP (Pierce) to anti-GluA2 polyclonal antibody were incubated overnight with the mixed proteins (160 $\mu \mathrm{l}$ of both GluA2 and CNIH-3), $160 \mu \mathrm{l}$ of GluA2 plus $160 \mu \mathrm{l}$ of buffer, and $160 \mu \mathrm{l}$ of CNIH-3 plus $160 \mu \mathrm{l}$ of buffer. After three washes bound protein was acid eluted and detected by Western blots using anti-GluR2 C-terminus (CT) and anti-FLAG antibody for GluA2 and CNIH-3, respectively.

\section{Purification of recombinant GluN1/GluN2B purification from \\ HEK cells}

Cell pellet was obtained from $40 \times 15 \mathrm{~cm}$ plates of GluN1wtGluN2B cells. The purification procedure was same as for GluA2, but the buffer was $50 \mathrm{~mm} \mathrm{Na-HEPES,} \mathrm{pH} \mathrm{7.4,} 300 \mathrm{~mm} \mathrm{NaCl}, 1 \mathrm{~mm}$ kynurenic acid, 10 $\mathrm{mM} \mathrm{MgSO}_{4}$, and $100 \mu \mathrm{M}$ ifenprodil throughout.

\section{Purification of GluA2 S1S2 extended linker (LBD)}

The GluA2 S1S2 extended linker construct was produced and purified as described previously (Chen et al., 1998) for the HS1S2I construct.

\section{Purification of GluA2 NTD}

Four hundred milliliters of OptiMEM (Gibco) culture supernatant from a GluA2NTD-8His-expressing HEK cell line was spun down at $3500 \mathrm{rpm}$ for $10 \mathrm{~min}$. The supernatant was adjusted such that the final solution contained $50 \mathrm{~mm}$ sodium phosphate buffer and $25 \mathrm{~mm}$ imidazole, $\mathrm{pH}$ 7.5. The media was gravity loaded onto a $\mathrm{Ni}^{2+}$ charged chelating Sepharose column that was pre-equilibrated with OptiMEM containing sodium phosphate buffer and imidazole, pH 7.5 (50 and $25 \mathrm{~mm}$, respectively). After the medium passed through and the column was washed with 10 column volumes of wash buffer (50 mM sodium phosphate buffer, $30 \mathrm{~mm}$ imidazole, $\mathrm{pH}$ 7.5), the bound protein was eluted from the column with $20 \mathrm{~mm}$ Tris- $\mathrm{HCl}, \mathrm{pH}$ 7.5, $250 \mathrm{~mm}$ imidazole, and $150 \mathrm{~mm} \mathrm{NaCl}$. The eluant was spun down at 35,000 rpm for $15 \mathrm{~min}$ and loaded for gel filtration. Peak fractions contained purified proteins.

\section{Purification of receptor complexes from rat and human brain}

These procedures were described previously (Shanks et al., 2012). Human brain (cortex) was obtained through the National Disease Research Interchange [researcher: John Yates (code YAJ2); The Scripps Research Institute: IRB-11-5719].

\section{Mass spectrometry}

Sample preparation. Bound proteins were eluted from the beads by incubation with Pierce elution buffer and TCA precipitated overnight. The precipitate was resuspended in $8 \mathrm{M}$ urea with ProteasMAX (Promega) per the instructions of the manufacturer. The samples were subsequently reduced by $20 \mathrm{~min}$ incubation with $5 \mathrm{~mm} \operatorname{tris}(2$ carboxyethyl)phosphine at room temperature and alkylated in the dark by treatment with $10 \mathrm{~mm}$ iodoacetamide for 20 additional minutes. The proteins were digested overnight at $37^{\circ} \mathrm{C}$ with Sequencing Grade Modified Trypsin (Promega), and the reaction was stopped by acidification.

Multidimensional protein identification technology. The protein digest was pressure loaded onto a $250-\mu \mathrm{m}$ inner diameter capillary packed with $2.5 \mathrm{~cm}$ of $10 \mu \mathrm{m}$ Jupiter C18 resin (Phenomenex), followed by an additional $2.5 \mathrm{~cm}$ of $5 \mu \mathrm{m}$ Partisphere strong cation exchanger (Whatman). The column was washed with buffer containing $95 \%$ water, $5 \%$ acetonitrile, and $0.1 \%$ formic acid. After washing, a $100-\mu \mathrm{m}$ inner diameter capillary with a $5 \mu \mathrm{m}$ pulled tip packed with $15 \mathrm{~cm}$ of $4 \mu \mathrm{M}$ Jupiter C18 resin (Phenomenex) was attached to the filter union, and the entire splitcolumn (desalting column-filter union-analytical column) was placed in line with an Agilent 1100 quaternary HPLC and analyzed using a modified five-step separation described previously (Washburn et al., 2001). The buffer solutions used were $5 \%$ acetonitrile $/ 0.1 \%$ formic acid (buffer A), 80\% acetonitrile/0.1\% formic acid (buffer B), and $500 \mathrm{~mm}$ ammonium acetate $/ 5 \%$ acetonitrile $/ 0.1 \%$ formic acid (buffer C). Step 1 consisted of a 75 min gradient from $0-100 \%$ buffer B. Steps $2-5$ had a similar profile except $3 \mathrm{~min}$ of $100 \%$ buffer A, 5 min of $x \%$ buffer C, a 10 min gradient from $0-15 \%$ buffer $B$, and a 105 min gradient from $10-$ $55 \%$ buffer B (except for step 5 in which the percentage for buffer B was increased from 10 to $100 \%$ ). The 5 min buffer $C$ percentages $(x)$ were 10 , 40,60 , and $100 \%$, respectively, for the five-step analysis. As peptides eluted from the microcapillary column, they were electrosprayed directly into an LTQ mass spectrometer (Thermo Finnigan) with the application of a distal $2.4 \mathrm{kV}$ spray voltage. A cycle of one full-scan mass spectrum (400-2000 m/z) followed by six data-dependent tandem mass spectrometry (MS/MS) spectra at a 35\% normalized collision energy was repeated continuously throughout each step of the multidimensional separation. Application of mass spectrometer scan functions and HPLC solvent gradients were controlled by the Xcaliber data system.

Analysis of tandem mass spectra. MS/MS spectra were analyzed using the following software analysis protocol. Poor quality spectra were removed from the dataset using an automated spectral quality assessment algorithm (Bern et al., 2004). MS/MS spectra remaining after filtering were searched with the ProLuCID algorithm against the EBIIPI_Human_3_30_06-28-2007 concatenated to a decoy database in which the sequence for each entry in the original database was reversed (Peng et al., 2003). All searches were parallelized and performed on a Beowulf computer cluster consisting of $1001.2 \mathrm{GHz}$ Athlon central processing units (Sadygov et al., 2002). Only peptides with at least one tryptic termini were considered. Searches were performed with cysteine carbamidomethylation as a fixed modification.

ProLuCID (Eng et al., 1994) results were assembled and filtered using the DTASelect (version 2.0) program (Tabb et al., 2002). DTASelect 2.0 uses a linear discriminant analysis to dynamically set XCorr and DeltaCN thresholds for the entire dataset to achieve a user-specified false-positive rate ( $5 \%$ in this analysis). The program estimates the false-positive rates from the number and quality of spectral matches to the decoy database. Confidence for modifications was estimated from overlapping modified peptides as described previously (MacCoss et al., 2002). 


\section{Immunoprecipitation of CNIH-HA proteins in HEK cells}

TetOnGluA2 flip cells were plated on $0.2 \%$ gelatin at a density of $0.5 \times$ $10^{6}$ cells $/ \mathrm{ml}$. Twenty hours later, cells were transfected with wild-type (WT) and mutant CNIH-3-HA constructs using the calcium phosphate method. Twenty-four hours after transfection, cells were washed with cold PBS twice and resuspended in $750 \mu \mathrm{l}$ of buffer containing $50 \mathrm{~mm}$ Na-HEPES, pH 7.4, $85 \mathrm{~mm} \mathrm{NaCl}, 15 \mathrm{~mm} \mathrm{KCl,} 30 \mu \mathrm{m} \mathrm{NBQX}$, and protease inhibitors ( $1 \mathrm{~mm}$ PMSF, $10 \mu \mathrm{g} / \mathrm{ml}$ leupeptin, atropinin, benzamidine, and pepstatin A). Cells were lysed with $0.25 \%$ DDM for $1.5 \mathrm{~h}$ at $4{ }^{\circ} \mathrm{C}$ and ultracentrifuged at 35,000 rpm (Beckman TLA-55 rotor) for $15 \mathrm{~min}$. The supernatant was incubated with anti-HA antibody (RRID: AB_10064069; catalog \#MMS-101R-1000; Covance) at a concentration of 1:300 for $\sim 15 \mathrm{~h}$. Thirty microliters of protein A Sepharose beads were added and incubated with the lysate for $3 \mathrm{~h}$. After washing the beads twice, protein was eluted from the beads by boiling with DTT/SDS loading buffer. Western blotting was done using anti-R2CT polyclonal antibody at 1:300 (Nakagawa et al., 2005) and anti-HA antibody at 1:1000 (RRID: AB_10064069; catalog \#MMS-101R-1000; Covance).

\section{Negative staining of purified proteins and EM}

Four hundred mesh copper grids were coated with carbon to create a substrate for proteins to bind. Four microliters of protein solution were applied to a glow discharged grid and left for $30 \mathrm{~s}$ to $5 \mathrm{~min}$ to allow the proteins to bind. The excess liquid was blotted on filter paper, and the grid was washed twice in water droplets to remove excess detergent. Purified proteins were negatively stained with $0.75 \%(\mathrm{w} / \mathrm{v})$ uranyl formate as described previously (Ohi et al., 2004). Images were recorded using a FEI Sphera electron microscope equipped with $\mathrm{a} \mathrm{LaB}_{6}$ filament operated at an acceleration voltage of $200 \mathrm{keV}$. Images were taken at a magnification of $50,000 \times$ and defocus value of $-1.5 \mu \mathrm{m}$. All images were recorded using SO-163 film and developed with Eastman Kodak D-19 developer at full strength for $12 \mathrm{~min}$ at $20^{\circ} \mathrm{C}$. Particle images were taken at room temperature and under low-dose conditions $\left(20 \mathrm{e} / \AA^{2}\right)$ to minimize radiation damage.

\section{Fab labeling}

The immunopure IgG1 $\mathrm{F}\left(\mathrm{ab}^{\prime}\right)$ and $\mathrm{F}\left(\mathrm{ab}^{\prime}\right) 2$ Fab purification kit (Pierce) was used to digest anti-HA monoclonal antibody (RRID: AB_10064069; catalog \#MMS-101R-1000; Covance). The Fab fragment was further purified by gel filtration on a Superdex 200 column (Pharmacia). Labeling of particles was performed by incubating the AMPAR/CNIH-3 particles with the Fab fragments at a molar ratio between 1:2 and 1:4 overnight at $4^{\circ} \mathrm{C}$ in $50 \mathrm{~mm}$ HEPES, pH 7.4, $100 \mathrm{~mm} \mathrm{NaCl}$, and $0.1 \%$ DDM.

\section{Image processing}

Electron micrographs were digitized with a CoolScan 9000 (Nikon) using a step size of $6.35 \mathrm{~mm}$. The pixels were binned by a factor of 3 such that the specimen level pixel size used was $3.81 \AA$. Projection averages were calculated from windowed small images of $100 \times 100$ pixels over 10 cycles of $K$-means classification and multi-reference alignment specifying 150 classes. A total of 9300 particles for GluA2 and 8951 particles for GluA2/CNIH-3 were interactively selected using the WEB display program for SPIDER (Frank et al., 1996).

\section{TMD width calculation and comparison}

The width of the TMD was measured at its widest point in NIH ImageJ (RRID: nif-0000-30467) for each class average. Class averages in which the TMD was not clear enough to be accurately measured were eliminated from calculations. This measurement was recorded in pixels and calculated back into angstroms. The measurement for each class average was attributed to the number of particles contained in that class average.

\section{Western blot/coimmunoprecipitation analysis}

Analysis was performed in NIH ImageJ by inverting colors of film images and analyzing the plot profile. The area for each band was recorded. For analysis of coimmunoprecipitations (CoIPs), the elution band of the coimmunoprecipitated protein was normalized to the input band to account for any potential differences in expression level. This value was then normalized to the elution band of the immunoprecipitated protein to account for any differences in immunoprecipitation efficiency. The values for conditions were then normalized to each other, so that the maximum value became 1 . For example, when comparing the $\mathrm{CNIH}-3$ mutants, the CNIH-3 WT value was 1, and the others were fractions of this. The conditions were compared with this maximal value using an unpaired $t$ test with Welch's correction or using one-way ANOVA, followed by Tukey's multiple comparisons tests.

\section{Time course of GluA2 expression in TetOnGluA2/CNIH-3HA cell lines}

Various clones of TetOnGluA2/CNIH-3HA cell lines and the parental TetOnGluA2 cells were plated at a density of $0.6 \times 10^{6}$ cells per well on six-well plates. At $24 \mathrm{~h}$ later, cells were induced with $2.5-7.5 \mu \mathrm{g} / \mathrm{ml} \mathrm{DOX}$ in the presence of $1 \mathrm{~mm}$ kynureic acid, $30 \mu \mathrm{M} \mathrm{NBQX}$, and $1 \mathrm{~mm} \mathrm{Na}-$ butyrate. At time points $0,6,12,18$, and $24 \mathrm{~h}$ after induction, cells were washed with PBS and harvested in $1 \mathrm{ml}$ of PBS. After spin down and aspiration of supernatant, cells were flash frozen in liquid $\mathrm{N}_{2}$. SDS-PAGE samples were prepared with $400 \mu \mathrm{l}$ of PBS and $200 \mu \mathrm{l}$ of $4 \times$ DTT SDSPAGE sample buffer and boiled for $15 \mathrm{~min}$. Western blotting was done using anti-HA (RRID: AB_10064069; catalog \#MMS-101R-1000; Covance) and anti-GluA2CT polyclonal antibodies (Nakagawa et al., 2005). Western blot films were scanned and analyzed using NIH ImageJ software (RRID: nif-0000-30467). Background-subtracted total signal at each time point was normalized to the signal at $24 \mathrm{~h}$ after induction. Three sets of experiments were conducted, and the band intensity of each time point of each cell line was averaged and plotted as a line graph.

\section{Immunocytochemistry in HEK cells}

Expression vectors were made by replacing WT CNIH-3HA with CNIH-3 mutants in pBOSS-CNIH-3HA-IRES-mCherry. HEK cells transfected with each plasmid were grown on poly-L-lysine-coated glass coverslips, washed briefly with PBS, and fixed with $4 \%$ formaldehyde in $0.1 \mathrm{~m}$ phosphate buffer, $\mathrm{pH} 7.4$, for $9 \mathrm{~min} \sim 24 \mathrm{~h}$ after transfection. Cells were permeabilized and then incubated in primary anti-HA at 1:1000 (RRID: AB_10064069; catalog \#MMS-101R-1000; Covance). Alexa Fluor 568- and Alexa Fluor 488-conjugated secondary antibodies were used at a dilution of 1:200 (Invitrogen). Images of the cells were recorded using an epifluorescence microscope (Olympus) and recorded on a cooled CCD camera (Hamamatsu Orca).

\section{Surface labeling of HEK cells}

In the bottom panels of Figure $4 D$, transfected cells were live labeled using anti-HA at 1:1000 (RRID: AB_10064069; catalog \#MMS-101R1000; Covance) for $15 \mathrm{~min}$ in plain DMEM. Cells were washed with warm DMEM and fixed with $4 \%$ formaldehyde in $0.1 \mathrm{~m}$ phosphate buffer, $\mathrm{pH}$ 7.4. Alexa Fluor 488-conjugated anti-mouse IgG secondary antibody (Invitrogen) was used for detection.

\section{Cell death assay experiments}

Each stable cell line was plated at a density of $\sim 0.2 \times 10^{6} \mathrm{cell} / \mathrm{ml}$ in a 12 -well plate. At $24 \mathrm{~h}$ after plating, differential interference contrast (DIC) images were taken of cells at $10 \times$ magnification. Cells were then induced with $7.5 \mu \mathrm{g} / \mathrm{ml}$ DOX and $1 \mathrm{~mm}$ Na-butyrate. The AMPAR antagonist NBQX $(30 \mu \mathrm{M})$ was used to inhibit cell death. At $30 \mathrm{~h}$ after induction, DIC images were taken of induced cells both with and without NBQX.

\section{Modified MTT cell proliferation assay}

A nonradioactive cell proliferation assay (G4000; Promega; also known as the modified MTT assay) was used. Each stable cell line was plated at 5000 cells per well in a 96-well plate. After cells were attached to the plastic for $1 \mathrm{~h}$, DOX and NBQX were supplemented according to the following three test groups: (1) group 1, $7.5 \mu \mathrm{M}$ DOX; (2) group 2, $40 \mu \mathrm{M}$ NBQX plus $7.5 \mu \mathrm{M}$ DOX); and (3) group 3, $40 \mu \mathrm{M}$ NBQX. For each cell line, each test group was replicated in eight wells, providing sufficient sampling for statistical analysis. Two days later, $15 \mu \mathrm{l}$ of tetrazolium salt dye solution was added to each well and further incubated in the $\mathrm{CO}_{2}$ incubator for $3 \mathrm{~h}$. The reaction was stopped by adding $100 \mu \mathrm{l}$ of stop solution to each well, and then the samples were incubated at $4^{\circ} \mathrm{C}$ for $4 \mathrm{~h}$. Absorbance at $570 \mathrm{~nm}$ was measured, and reference was taken at absor- 
bance $700 \mathrm{~nm}$ according to the assay method [protocol provided by Promega (G4000) and Mosmann, 1983].

\section{Peptide array experiments}

The peptide arrays were synthesized using SPOT synthesis (Frank, 1995). Two arrays were synthesized separately, one for CNIH-1 and one for CNIH-3. Each dot on the array corresponds to 20 aa of the protein. Each subsequent dot contains another 20 aa, each time shifted by 3 aa moving from the $\mathrm{N}$ to the $\mathrm{C}$ terminus. In the first peptide array experiments (see Fig. 3) probed with the full-length GluA2, the entire CNIH-3 and $\mathrm{CNIH}-1$ sequences are represented. In the second set of peptide array experiments (see Fig. 6), the peptide sequence begins at the $\mathrm{N}$ terminus of CNIH- 3 and extends partway through the second TMD, highlighting the first TMD and the first extracellular loop. In the latter, each dot on the array corresponds to 15 aa of the protein. Each subsequent dot contains another 15 aa, each time shifted by 2 aa. In all cases, membranes were washed sequentially with methanol, water, protein purification buffer, and blocking buffer ( purification buffer with 5\% BSA) for $10 \mathrm{~min}$. Then the peak fractions of protein from gel filtration of full-length GluA2 purified from HEK cell, S1S2 extended linker protein, or GluA2 NTD (as described above) were added to the blocking buffer and incubated on the membranes at $4^{\circ} \mathrm{C}$ for $4 \mathrm{~h}$. After washing the array with purification buffer, using the procedures analogous to conventional Western blotting, the membrane was probed using anti-GluA2CT antibody (Nakagawa et al., 2005) as the primary probe and HRP-conjugated anti-rabbit IgG as the secondary probe to detect full-length GluA2-positive dots or the penta-His HRP conjugate antibody (Qiagen) to detect GluA2 S1S2 or NTD-positive dots. The signal was detected using the chemiluminescent method and recorded on film.

\section{Analysis of peptide array results}

The dots on the film were visually identified as either positive or negative for GluA2 interaction. The amino acid sequences corresponding to each dot were checked. A histogram was created such that the appropriate sequences of $\mathrm{CNIH}-1$ and $\mathrm{CNIH}-3$ form the horizontal axis. Each point of the horizontal axis corresponds to a single residue of each protein, and the number of positive dots containing each residue was recorded on the vertical axis. Amino acids with more positive dots would have stronger interaction with GluA2. Stretches of amino acids with positive scores were identified. These amino acid clusters were interpreted as positive for a GluA2 interaction. These positive residues were altered in the series of CNIH-3 alanine substitution mutants.

\section{Electrophysiology}

Voltage-clamp recordings were performed on outside-out patches from HEK293T cells as described previously (Rossmann et al., 2011). Cells were transfected with GluA2-Q (flip) and CNIH-3 or CNIH-1 plasmids or with GluA2-Q (flip) alone. Current responses of outside-out patches (voltage clamped at $-60 \mathrm{mV}$ ) were elicited by fast application of $10 \mathrm{~mm}$ L-glutamate via a $\Theta$-tube and recorded using an Axopatch-1D amplifier, Digidata1322 interface, and pClamp 9.2 software (Molecular Devices). The rate of receptor desensitization was quantified by fitting the current decay during a $200 \mathrm{~ms}$ application of L-glutamate with a doubleexponential function and calculating the weighted time constant of desensitization $\left(\tau_{\text {des }}\right)$.

\section{Results}

\section{Purification of the CNIH-3-GluA2 complex}

The CNIH family consists of four family members CNIH-1 to CNIH-4, yet only CNIH-2 and CNIH-3 have been shown to interact with AMPARs in rat brain (Schwenk et al., 2009; Shanks et al., 2012). The basic topology of all the CNIH homologs is preserved, but $\mathrm{CNIH}-2$ and $\mathrm{CNIH}-3$ contain additional unique sequences within the extracellular loop that are absent in CNIH-1 and CNIH-4 (Fig. 1 A,C). To study the biochemical properties of the receptor complex, GluA2 and $\mathrm{CNIH}-3$ were coexpressed in a stable HEK cell line using DOX induction (Fig. $1 B, G$ ). We then purified GluA2 by immunoaffinity chromatography, followed by gel filtration chromatography (Fig. 1D). CNIH-3 copuri- fied with GluA2, because CNIH-3 coeluted with GluA2 in gel filtration fractions 17-20 (Fig. 1E,F). The peaks of GluA2 purified from GluA2 and GluA2/CNIH-3-expressing cells are shown in Figure $1 D$.

Western blots of the gel filtration fractions probed with GluA2 confirm the presence of CNIH-3 (Fig. $1 F$ ) and show that a portion of CNIH-3 "falls off" the AMPAR complex during the chromatography and is present in later fractions 27-29, corresponding to lower-molecular-weight proteins (Fig. $1 F$ ). A large subset of CNIH-3 copurifies with AMPARs in gel filtration fractions 17-20, corresponding to tetrameric AMPARs, indicating stable complex formation between $\mathrm{CNIH}-3$ and tetrameric GluA2.

\section{CNIH-3 affects parameters of AMPAR biogenesis}

A role of CNIHs was reported to be in AMPAR forward trafficking, possibly by functioning as a molecular chaperone (Schwenk et al., 2009; Shi et al., 2010; Herring et al., 2013). However, it is unclear whether CNIHs have chaperone function that accelerates AMPAR biogenesis. To address this, we used the expression strategy shown in Figure $1 B$, established several cell lines expressing varying levels of CNIH-3, and compared the time course of GluA2 expression after DOX induction (Fig. $1 H$ ), an approach used previously to study AMPAR biogenesis (Shanks et al., 2010). Notably, in a cell line that expresses the highest level of CNIH-3 (clone GluA2flip CNIH-3HA\#5), GluA2 level was decreased by more than fivefold (Fig. $1 G$ ), indicating that CNIH-3 does not enhance the production of GluA2 at steady state. This does not exclude the possibility that, in neurons, $\mathrm{CNIH}-3$ could exert chaperone function in concert with specific neuronal factors.

We next examined the rate at which GluA2 reaches its maximum level of expression. For this purpose, we defined the normalized rate of expression of GluA2 at a given time point as the amount expressed at each time point relative to the maximum attainable level of GluA2 expression. The $24 \mathrm{~h}$ time course of normalized rate of GluA2 expression was indistinguishable in all of the cell lines (Fig. $1 H, I$ ).

The glycosylation pattern of GluA2, and hence trafficking through the secretory pathway, was different between $\mathrm{CNIH}-3$ expressing and CNIH-3-lacking cell lines, an observation consistent with previously reported data (Shi et al., 2010; Harmel et al., 2012; Brockie et al., 2013; Herring et al., 2013). When we digested GluA2 expressed in each cell line with peptide $-N$-glycosidase F (PNGaseF) and endoglycosidase $\mathrm{H}$ (EndoH), the EndoH digested product migrated faster for GluA2 coexpressed with CNIH-3 (Fig. 1J). Together, these data point out that $\mathrm{CNIH}-3$ has a complex effect on AMPAR maturation in the secretory pathway.

\section{EM structure of the GluA2/CNIH-3 complex}

CNIH-2 and CHIH-3 interact with AMPARs and comigrate in blue native PAGE (Schwenk et al., 2009; Shi et al., 2010; Kato et al., 2010), but it is unknown whether this observed stability is accompanied by a structurally intact AMPAR complex. Therefore, we used negative stain EM to compare the shapes of the detergent solubilized GluA2 homotetrameric AMPAR particles in the presence or absence of CNIH-3.

The ultrastructure of the GluA2 tetramer expressed and purified from HEK cells is similar in structure to native AMPARs purified from rat brain (Nakagawa et al., 2005; Shanks et al., 2010). Specifically, the large globular density at the bottom of the particle is the TMD, the two smaller roundish domains directly above are the LBDs, and the two larger elongated bipartite den- 
A

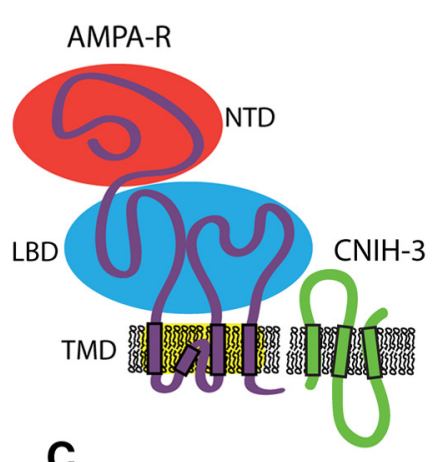

C

CNIH-3 4 LVLCAALIFFAIWHIIAFDELRTDFKSPIDQCNPVHARERLRNIERICFLLRKLVLPEYSIHSLFCVMFLCAQEWLTI CNIH-2 LVLCASLIFFVIWHIIAFDELRTDFKNP IDQGNPARARERLKNIERICCLIRKLVVPEYSIHGLFCLMFLCAAEWVTI CNIH-1 LLLTAALIFFAIWHIIAFDELKTDYKNP IDOCN--------------TLNPLVLPEYLIHAFFCVMFLCAAEWLTI $\begin{array}{ll}\text { CNIH-1 } & \text { LLLTAALIFFAIWHIIAFDELKTDYKNPIDQCN------------------TLNPLVLPEYLIHAFFCVMFLCAAEWLTI } \\ \text { CNIH-4 } & \text { LIDCCSLIFLSVYFIITLSDLECDYINARSCCS----------------KLNKWIPELVGHTFVTVLMLVSLHWVIF }\end{array}$

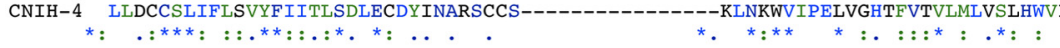

$\mathbf{E}$

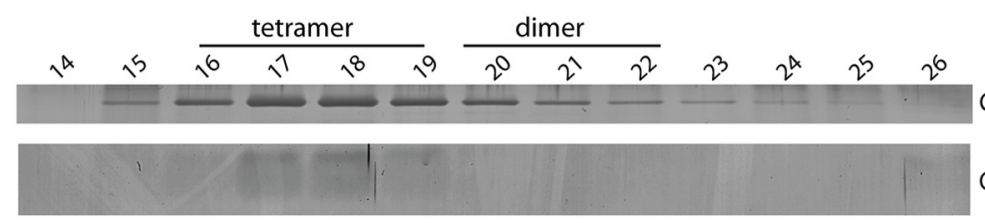
GluA2

\section{$\mathbf{F}$}
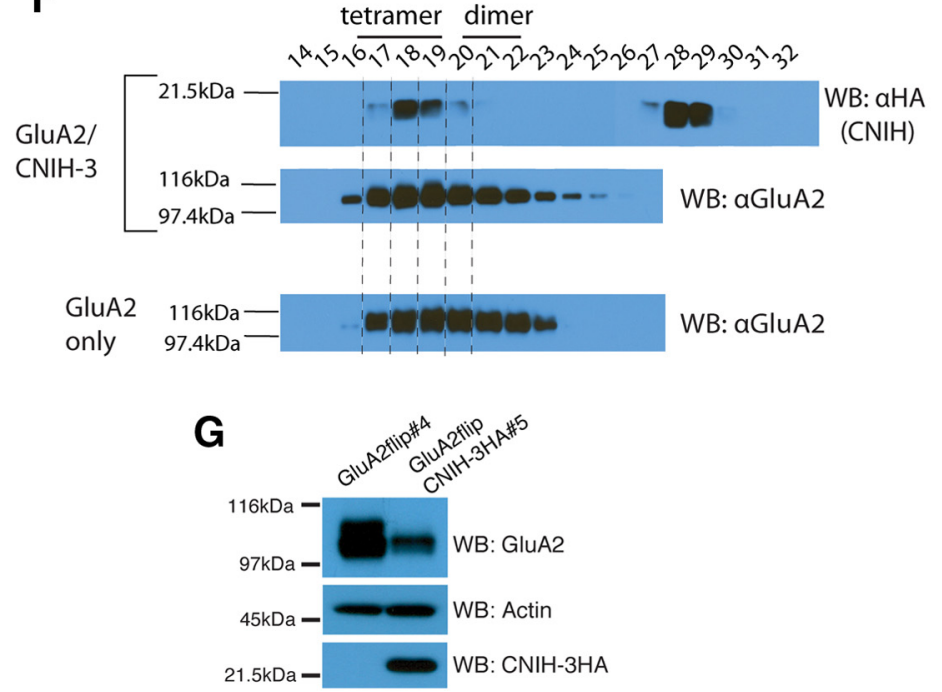

$\mathrm{CNIH}-3$

$\mathbf{J}$
D

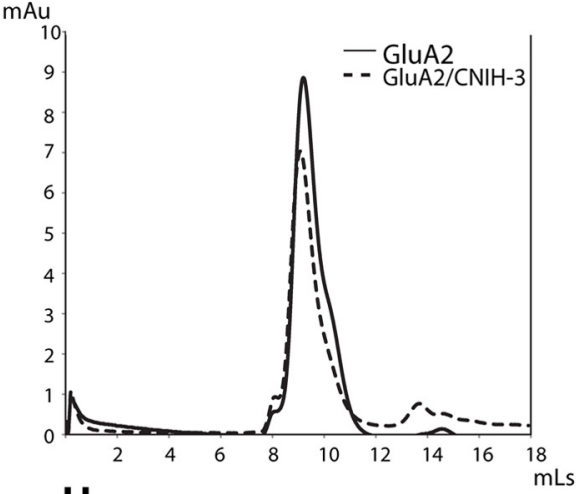

H

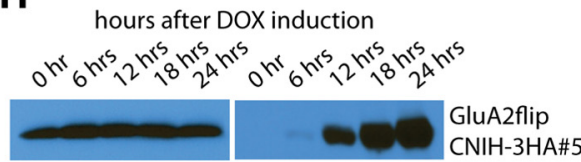

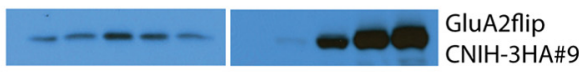
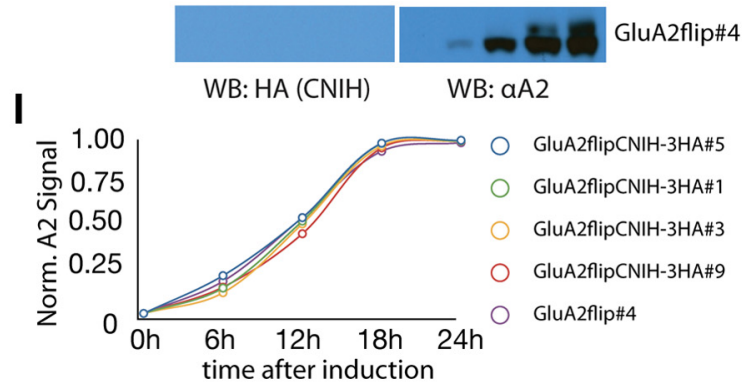

GluA2flip

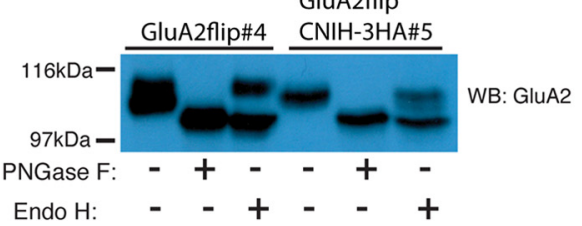

Figure 1. Copurification of CNIH-3 with the GluA2 complex. A, Topology of AMPAR subunit and CNIH in the lipid bilayer. B, Schematic of the strategy to coexpress GluA2 and CNIH-3HA in HEK cells: the TetOn system of protein induction in which the addition of DOX to the cell media promotes GluA2-FLAG production in a cell line that constitutively expresses CNIH-3HA-IRES-mCherry. rtTA, Reverse tetracycline-controlled transactivator; TRE, Tet-response element; EF1, elongation factor promoter C, Amino acid sequence alignment of the extracellular loop regions of CNIHs between TM1 and TM2. D, Gel filtration chromatograph of purified GluA2 alone (solid line) and GluA2/CNIH-3 (dotted line). E, Silver-stained SDS-PAGE resolving the gel filtration fractions of the GluA2/CNIH-3 purification. Note the presence of both GluA2 and CNIH-3.F, Western blotting (WB) of the gel filtration fractions of the GluA2/CNIH-3 purification (top 2 panels) and GluA2 only purification (bottom) probed with either HA antibody to recognize $\mathrm{CNIH}-3$ or anti-GluA2 antibody. CNIH-3 is present in the same fractions as GluA2, demonstrating that they copurify. Each fraction is $0.5 \mathrm{ml}$, and fraction 18 corresponds to elution volume $9.5-10 \mathrm{ml}$. G, Western blots comparing the total expression level of GluA2 in two cell lines. Actin was used as an internal control to ensure that an equal number of cells was loaded in each lane. $\boldsymbol{H}$, Western blots showing the time course of protein expression after addition of DOX to the HEK cell media in the GluA2-expressing parental cell line (bottom) and different GluA2/CNIH-3 coexpressing cell lines (above). GluA2 expression shown on the left and CNIH-3HA expression on the right. Smaller amount of lysate from GluA2flip\#4 was loaded to account for the difference in total expression level of GluA2, as indicated in G. I, Quantification of GluA2 (A2) expression time course after induction in different cell lines. Signal densities are normalized to the $24 \mathrm{~h}$ time point. J, Western blot showing the PNGase- and EndoH-digested GluA2 that was expressed with or without CNIH-3.

sities at the top are the two dimers of the NTDs (Fig. 2A). The domains of the GluA2 homotetramer were well defined in both the absence and presence of CNIH-3.

We observed that the TM region (bottom density) is wider in the particles of the GluA2/CNIH-3 complex when compared with GluA2 alone. This observation was consistent in both the raw particle images (Fig. $2 B$, top images) and the class averages (Fig. 2B, smaller bottom images). The mean TM density width was 101 and $126 \AA$ in the absence and presence of $\mathrm{CNIH}-3$, respectively (Fig. 2C). 

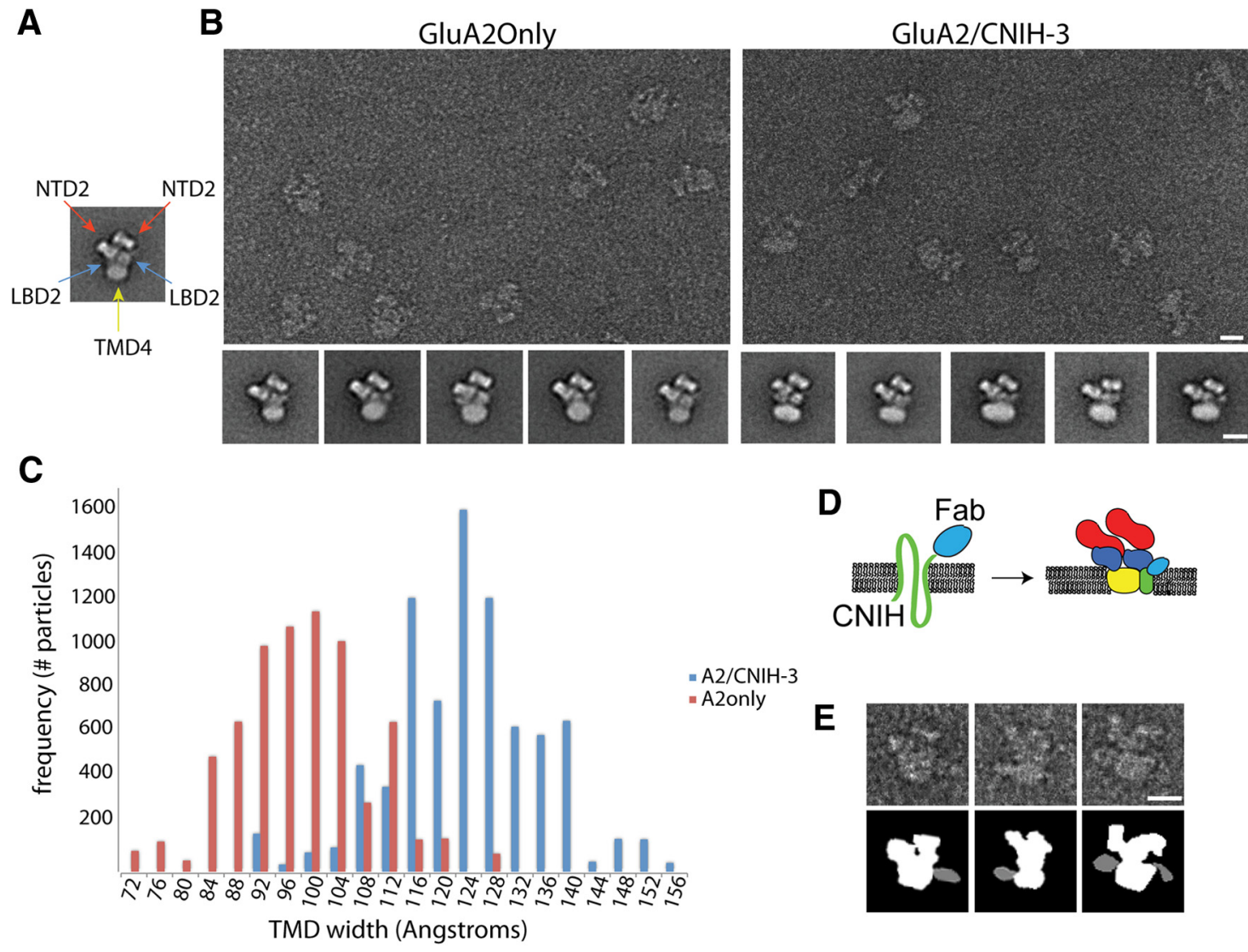

Figure 2. $\quad$ CNIH-3 contributes to the membrane density of the GluA2 complex. A, Tetrameric recombinant AMPAR class average marked with domain assignments. Numbers represent the dimeric (2) or tetrameric (4) nature of the labeled domain. B, Representative raw images (top) and representative class averages (bottom) of GluA2 only (left) and GluA2/CNIH-3 (right) particles. Scale bars, $10 \mathrm{~nm}$. C, Histogram of the TMD widths of the particles from GluA2 (red; A2 only) and GluA2/CNIH-3 (blue; A2/CNIH-3) particles demonstrating a clear shift in size. D, Diagram schematic of anti-HA Fab fragment labeling of the extracellular C terminus of CNIH-3 in relation to the AMPAR complex. $E$, Raw images of representative Fab labeled AMPAR particles (top) and a diagram version of each raw image to facilitate interpretation (bottom) in which the receptor complexes are shown in white and the Fab fragments in gray. Scale bar, $10 \mathrm{~nm}$.

The EM structure was further interpreted by molecular labeling. The HA epitope is located at the extracellular $\mathrm{C}$ terminus of CNIH-3. The anti-HA Fab fragments consistently bound to AMPAR TM density on the extracellular side of the protein complex (Fig. 2E), consistent with CNIH-3 contributing the increased TM density to AMPAR complex and further validating the predicted topology of the CNIHs (Fig. 2D). Although most Fab-labeled AMPAR particles were decorated by only one Fab fragment, a small subset seemed to have two Fabs (Fig. 2E, leftmost particle). These images clearly show the presence of at least one CNIH-3 molecule contributing to the TMD of the AMPAR complex and suggest that more than one CNIH-3 molecule can interact with each complex. We emphasize that, because of the limited affinity between Fab and its HA epitope, this approach cannot be used quantitatively to determine the population of particles that contain multiple molecular copies of CNIH-3. In fact, the probability of two Fabs binding to a given complex is proportional to the product of the probability of first and second Fab binding and thus the population of particles having two $\mathrm{CNIH}-3$ s are underrepresented. Our qualitative approach clearly identifies a subset of particles that have two Fabs bound and positively demonstrates instances in which multiple $\mathrm{CNIH}-3$ s are bound to a single GluA2 tetramer. Considering that a significant portion of the CNIH-3 falls off during the purification (Fig. $1 F$ ), the TMD of the resulting GluA2/CNIH-3 complex is still larger than the GluA2 tetramer without CNIH-3. Collectively, these results imply that multiple CNIHs can associate with a single GluA2 tetramer to form a detergent-resistant and stable complex.

\section{In vitro reconstitution of the $\mathrm{CNIH}-3$ and GluA2 complex}

The formation of complexes between membrane proteins may require the lipid bilayer. To test whether the GluA2/CNIH-3 complex can be reconstituted in vitro in the presence of detergent, we individually FLAG affinity purified CNIH-3-3xFLAG and GluA2-FLAG that were expressed separately. We mixed the two proteins to examine whether they interact. CNIH-33xFLAG specifically coimmunoprecipitated with GluA2FLAG when pulled down using anti-GluA2CT antibody that recognizes the endogenous C-terminal peptide of GluA2 (Fig. $3 A, B)$. No CNIH-3-3xFLAG was detected in the elution of the immunoprecipitate in the absence of GluA2-FLAG. This indicates a robust interaction between these two proteins even in the absence of a cellular membrane and forms a basis for additional investigation of the interaction in a noncellular system.

\section{Membrane proximal residues in CNIH-3 important for complex formation}

To systematically identify residues of $\mathrm{CNIH}-3$ that are involved in the interaction with GluA2, we created two peptide array membranes that contained circles on which peptides derived from the sequences of CNIH-1 and $\mathrm{CNIH}-3$ were di- 
A

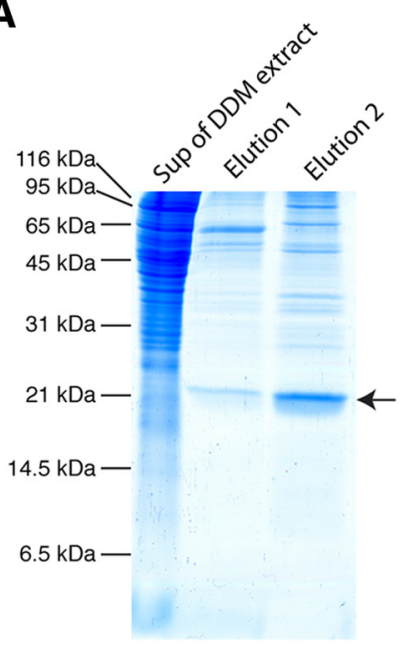

B

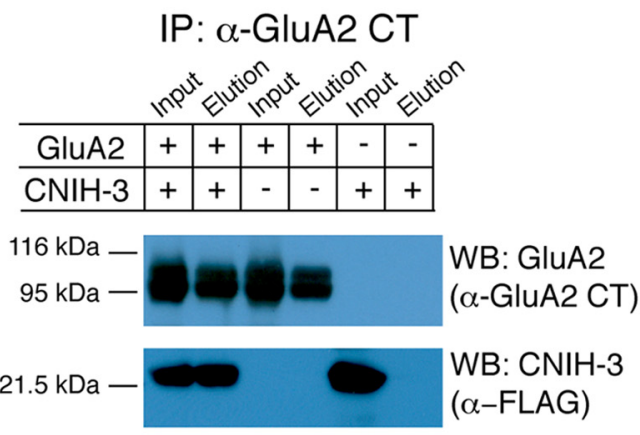

C

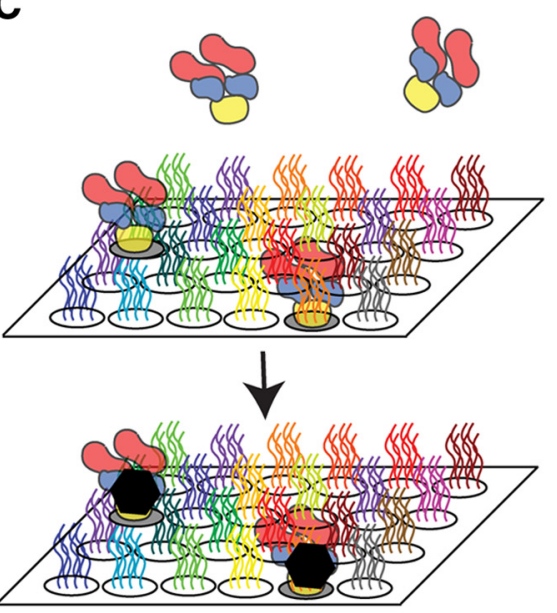

D

CNIH-3

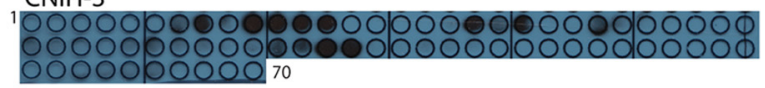

$\mathbf{E}$

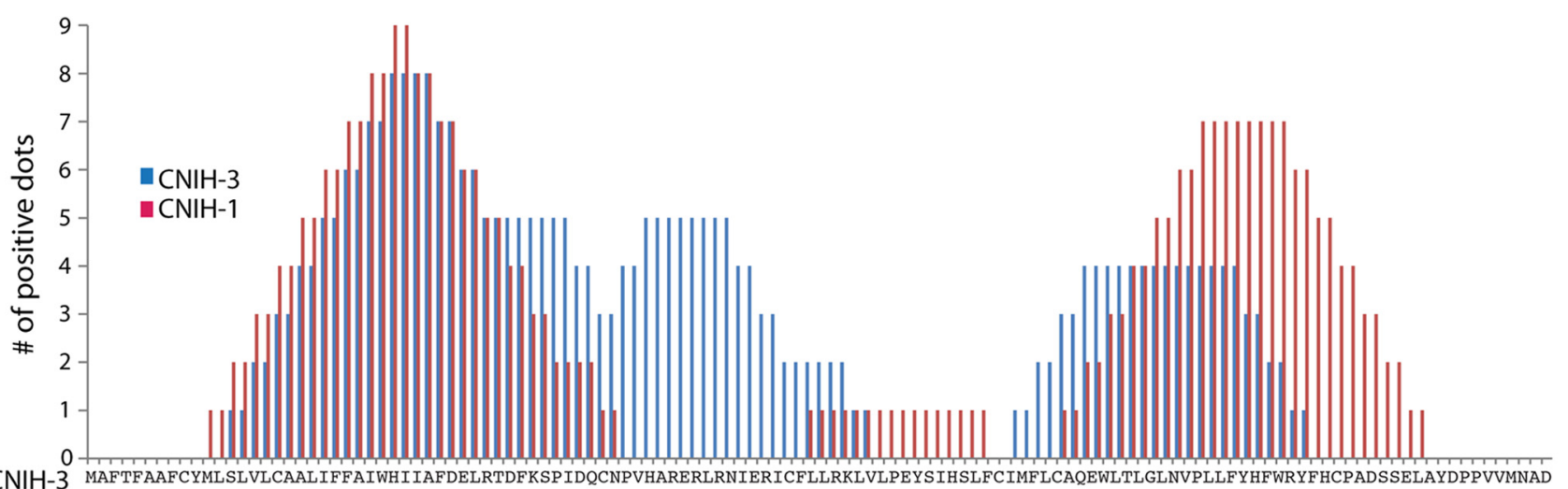

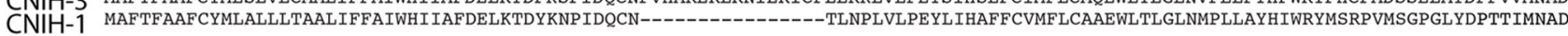

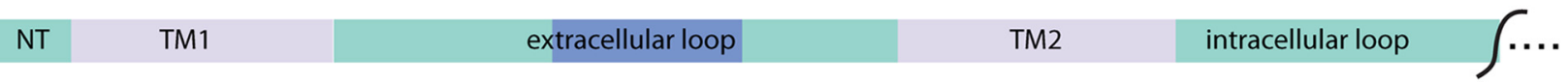

Figure 3. In vitro peptide array screening of CNIHs. A, Coomassie Brilliant Blue stained SDS-PAGE summarizing the FLAG tag affinity purification of CNIH-3-3xFLAG protein that was expressed in TetOnHEK cells. High-speed supernatant of DDM extracted cell lysate and two 3xFLAG peptide elutions are shown. Arrow indicates the FLAG tag affinity-purified CNIH-3-3xFLAG. B, Western blot (WB) of a ColP experiment: FLAG tag affinity-purified CNIH-3-3xFLAG and GluA2-FLAG were prepared and mixed in a tube. Tubes that contain only one protein were used as negative controls. GluA2 was pulled down using anti-GluA2CT antibody. Western blots were probed with anti-FLAG antibody to recognize recombinant CNIH-3 and anti-GluA2CT antibody. This demonstrates a robust interaction between the proteins in vitro. C, Diagram of peptide array assay. The 20 aa peptides spanning the entire CNIH-3 protein shifted by 3 aa are synthesized on a membrane. Purified AMPAR protein is incubated on peptide arrays, and Western blotting is performed to determine to which peptides AMPARs are bound. $\boldsymbol{D}$, Western blot of peptide array. The top left dot on each array represents the first 20 aa of the protein. Dots go from left to right to cover the whole sequence. Blackened dots are positive for AMPAR binding. $E$, Histogram representing the number of positive dots for each amino acid in the aligned protein sequences (shown across $x$-axis with CNIH-3 on the top and CNIH-1 on the bottom). CNIH-3 is represented in blue and CNIH- 1 in red. Below the amino acid sequences on the $x$-axis is a schematic showing the corresponding domain assignments: NT, N terminus, intracellular and extracellular loops; CT, C terminus (all in green). TM1 and TM2 are shown in violet. The region present in $\mathrm{CNIH}-3$ but lacking in $\mathrm{CNIH}-1$ is shown in blue. AMPAR binding was not detected beyond the intracellular loop, and thus this is not shown in the histogram.

rectly synthesized (Frank, 1995). Each peptide was 20 aa in length, the neighboring peptide overlapped by $17 \mathrm{aa}$, and the entire array spanned the full sequence of both CNIHs. We incubated the two arrays with purified intact GluA2 homotetrameric AMPARs and then probed for receptors that were bound to the membrane-immobilized peptides using an antiGluA2 antibody. The secondary antibody and detection techniques used for conventional Western blotting were adopted to identify dots on the membrane that were positive for AMPAR binding (Fig. 3C). By using this sensitive method, we identified short stretches within the CNIH proteins that directly interact with AMPARs (Fig. $3 C$ ). The data are quantified in a histogram by recording how many peptides containing a particular amino acid were positive in the peptide array blot in either blue (CNIH-3) or red (CNIH-1; Fig. 3D). This result identified regions of the extracellular and intracellular loops adjacent to the first two TM segments as candidate AMPAR binding regions common between $\mathrm{CNIH}-1$ and $\mathrm{CNIH}-3$. It also implicates the portion of the extracellular loop specific to $\mathrm{CNIH}-2 / 3$ as an additional possible interacting segment. No 
AMPAR binding was detected beyond the intracellular loop, and therefore this part of sequences of CNIHs is omitted from the histogram.

\section{Identification of specific $\mathrm{CNIH}$ residues critical for AMPAR binding}

To further narrow down the critical residues within the regions of CNIH-3 that showed highly positive AMPAR binding, we sequentially mutated three residues at a time to alanines. For example, DEL32AAA mutant denotes the conversion of the residues DEL to AAA, in which the number in the middle represents the location of the first amino acid that was mutated. Nine of the 12 mutants expressed in HEK cells (Fig. 4A-C). We coexpressed each of these mutants with GluA2 in HEK cells and tested their ability to interact with GluA2 in CoIP experiments. Although the nine mutants were expressed at approximately equal levels, three mutants, DEL32AAA, VPL104AAA, and LFY107AAA, showed significantly reduced interaction with GluA2 $(p=0.0001$, 0.0029 , and 0.0011 , respectively, using unpaired $t$ test, $n=3$; Fig. $4 A, B$, stars). The subcellular localization and surface expression of the CNIH-3 mutants were indistinguishable from that of the WT, as shown by their similar total and surface protein distributions (Fig. $4 D$, top and bottom, respectively). Thus, the loss of interaction is unlikely to be the result of protein mislocalization. Residues in the extracellular loop specific to CNIH-3 appeared as binding candidates in the peptide array experiments, but none of the three mutants in this area (RER61AAA, LRN64AAA, and IER67AAA) exhibit reduced interaction with GluA2. Collectively, these results identify specific residues in the CNIH-3 molecule that are critical for binding to the AMPAR, located in two distinct regions: the DEL sequence in the membrane-proximal extracellular loop regions and the VPLLFY sequence in the membrane-proximal cytoplasmic region.

\section{Parallel reduction in functional and physical interaction in CNIH-3 mutants}

CNIH-3 slows AMPAR desensitization (Schwenk et al., 2009; Kato et al., 2010; Shi et al., 2010; Coombs et al., 2012). We compared WT CNIH-3 and the CNIH-3 mutants identified to have reduced physical interaction (Fig. $4 B$ ) in their ability to modulate AMPAR desensitization. AMPAR desensitization kinetics were recorded with glutamate application to outside-out patches obtained from HEK cells coexpressing the CNIH-3 constructs with GluA2. Consistent with previous reports (Schwenk et al., 2009; Coombs et al., 2012), the addition of WT CNIH-3 dramatically slows receptor desensitization $\left(\tau_{\text {des }}=64.5 \pm 4.5 \mathrm{~ms}, n=11\right)$ compared with its absence ( $\left.\tau_{\text {des }}=4.8 \pm 0.2 \mathrm{~ms}, n=27\right)$. Interestingly, all of the CNIH mutants that showed reduced physical interaction with GluA2 featured reduced ability to modulate AMPAR desensitization kinetics compared with WT CNIH-3, resulting in $\tau_{\text {des }}$ values intermediate between those of WT CNIH-3 and no CNIH-3 at all (Fig. 4E, F; Table 1). Therefore, reduced binding to the receptor appears to attenuate the modulatory action of CNIH-3.

\section{Specificity of interaction between CNIHs and AMPARs}

The residues mediating AMPAR interaction in $\mathrm{CNIH}-3$ are well conserved in CNIH-1, raising the question of what determines the specificity of interaction. Therefore, we tested whether CNIH-1 physically interacts with GluA2. Interestingly, when coexpressed in HEK cells, rat GluA2 coimmunoprecipitates with rat CNIH-1, CNIH-2, and CNIH-3 (Fig. 5A). In addition, using MS, we found that all homologs, CNIH-1 to CNIH-4, copurify with
GluA2 from human brain (Fig. $5 B, C$ ), thus providing the first evidence for an involvement of CNIH-1 and CNIH-4 in AMPAR function in human brain. Furthermore, we found that small amounts of HEK cell-derived endogenously expressed CNIH-1 and CNIH-4 in addition to CNIH-3 copurify with recombinant rat GluA2 overexpressed in HEK cells (Fig. 5D). No endogenous CNIHs were copurified when heterotetrameric NMDARs made of GluN1 and GluN2B were overexpressed and purified from HEK cells, serving as a negative control. Collectively, our results highlight species differences in the molecular composition of endogenous AMPAR/CNIH complexes. We hypothesize that the regional difference in $\mathrm{CNIH}-1$ expression and perhaps greater coexpression with GluA2 in humans compared with rats could contribute to the difference in the molecular composition of the AMPAR complexes between the two species. The protein sequences of human and rat CNIH-1 are conserved, and thus interaction between rat CNIH- 1 and GluA2 should share molecular mechanism with human homologs.

CNIHs interact specifically with AMPARs and not with kainate receptors in the brain under our immunoprecipitation conditions, as shown by Western blot (Fig. $5 E$ ) and by MS previously (Shanks et al., 2012) This specificity is reproducible in HEK cells. When we immunoprecipitated $\mathrm{CNIH}-3$ from detergentextracted membranes of HEK cells coexpressing CNIH-3 and either GluA2 or GluK2, a significant amount of GluA2 coprecipitated with CNIH-3, whereas GluK2 did not $(p<0.0001$ using unpaired $t$ test, $n=5$; Fig. $5 F$ ). This result suggests that CNIH-3 recognizes the difference in amino acid sequences between AMPA and kainate receptor subunits, supporting specificity in binding.

\section{Functional interaction between CNIH-3 and GluA2 in HEK cells}

CNIH-2 and CNIH-3 but not CNIH-1 are known to modulate AMPARs by slowing AMPAR deactivation and desensitization kinetics in HEK cells (Schwenk et al., 2009; Kato et al., 2010; Shi et al., 2010; Coombs et al., 2012). Consistently, the effect of CNIH-1 coexpression on GluA2 desensitization kinetics was significant but was much weaker than for CNIH-3 $\left[\tau_{\text {des }}=5.2 \pm 0.1 \mathrm{~ms}(n=\right.$ 6) and $13.1 \pm 1.0 \mathrm{~ms}(n=9)$ for GluA2 with and without CNIH-1, respectively; $p=6.76 \mathrm{E}-05$, unpaired $t$ test with Welch's correction for unequal variances; (Fig. 4E, F; Table 1)]. The expression of GluA2 in the presence of the AMPAR auxiliary subunit stargazin in HEK cells results in cytotoxicity that can be prevented by the AMPAR antagonist NBQX. Because both stargazin and CNIHs enhance surface trafficking of AMPARs and increase charge transfer through the channel (Fig. 4E; Schwenk et al., 2009; Kato et al., 2010; Shi et al., 2010), we examined whether coexpression of CNIHs and GluA2 has similar cytotoxicity in HEK cells. In fact, the addition of either CNIH-3 or stargazin, but not CNIH-1, in the DOX-inducible GluA2-expressing HEK cells significantly increased the amount of cell death that occurred $30 \mathrm{~h}$ after DOX induction (Fig. 5G). The competitive AMPAR antagonist NBQX blocked the cell death.

To quantify this observation, we conducted a nonradioactive cell proliferation assay that optically detects the metabolic conversion of tetrazolium salt to a formazan product that takes place in proliferating cells. The quantity of formazan detected by optical absorbance at $570 \mathrm{~nm}$ correlates with the ability of cells to proliferate (Mosmann, 1983; Campling et al., 1988; Jover et al., 1994). Cell proliferation of various stable HEK cells were compared in the presence or absence of NBQX after inducing protein expression of GluA2 with DOX. The growth of cell lines coex- 
A

NT TM1 extracellularloop TM2 intracellular loop

B

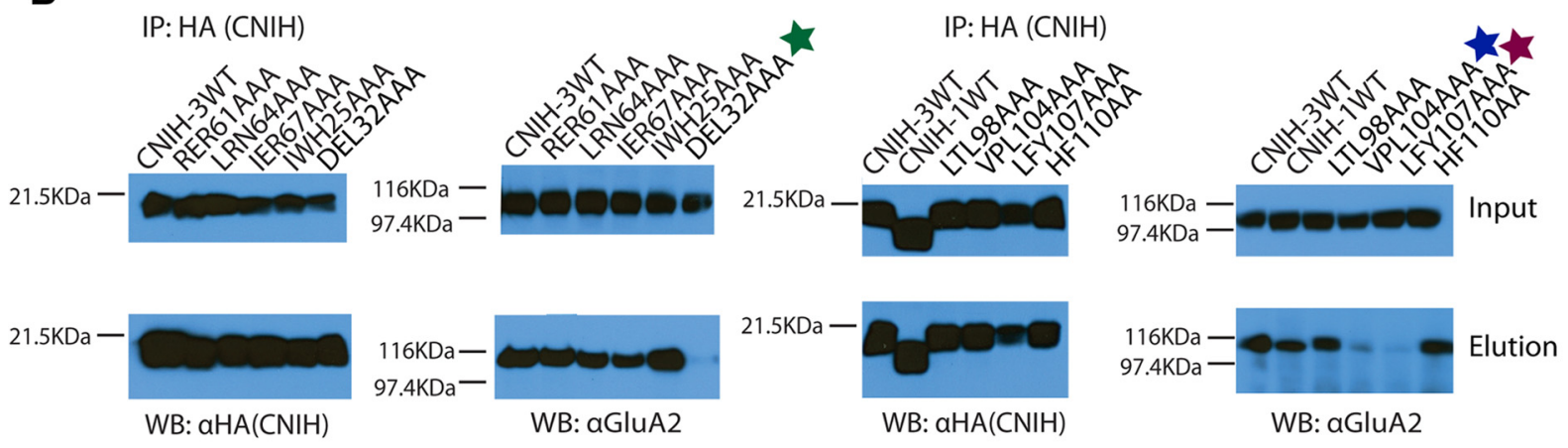

C

\begin{tabular}{|l|l|}
\hline CNIH-3 mutant & Interaction with GluA2 \\
\hline IWH25-27AAA & normal \\
\hline IIAF28-31AAAA & does not express \\
\hline DEL32-34AAA & reduced \\
\hline RER61-63AAA & normal \\
\hline LRN64-66AAA & normal \\
\hline IER67-69AAA & normal \\
\hline ICF70-72AAA & does not express \\
\hline LTL98-100AAA & normal \\
\hline GLN101-103AAA & does not express \\
\hline VPL104-106AAA & reduced \\
\hline LFY107-109AAA & reduced \\
\hline HF110-111AA & normal \\
\hline
\end{tabular}

D
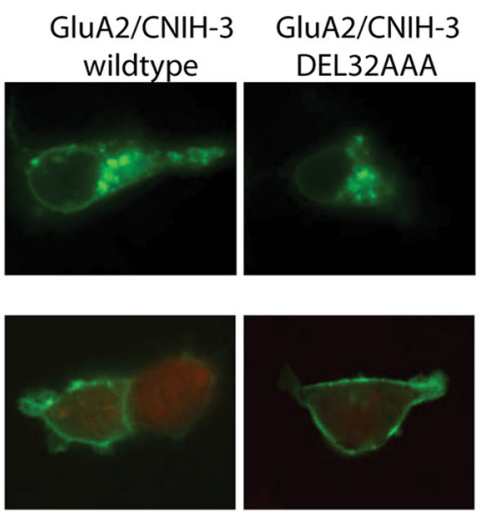

GluA2/CNIH-3 GluA2/CNIH-3 VPL104AAA LFY107AAA
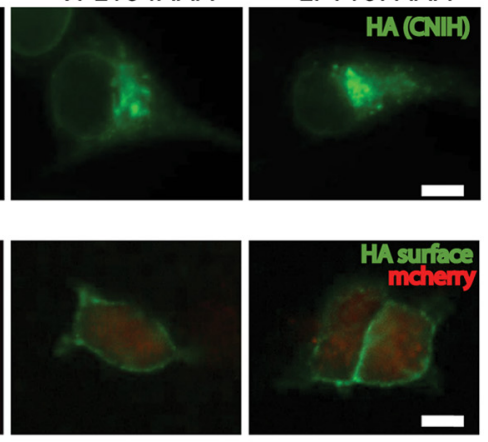

E

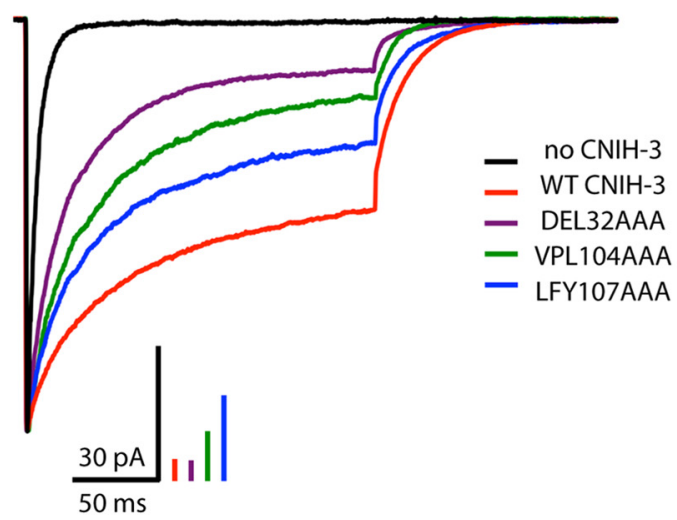

$\mathbf{F}$

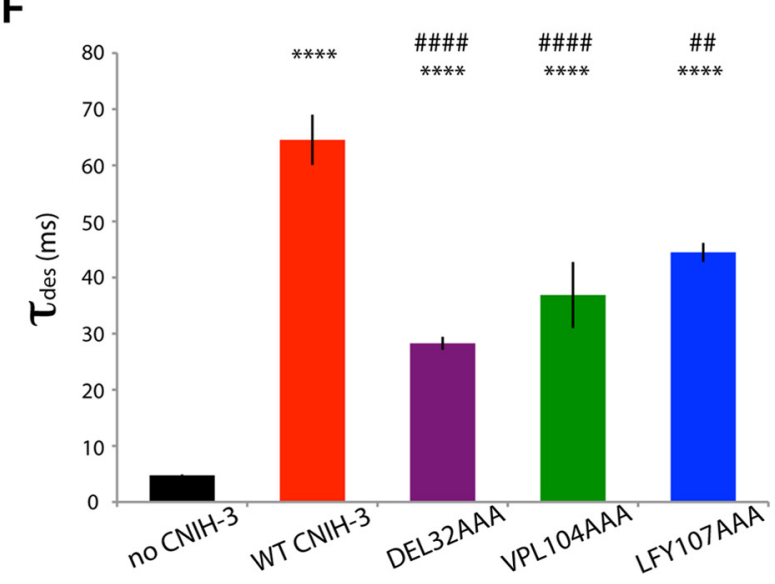

Figure 4. Identification of specific CNIH-3 residues critical for interaction with GluA2. A, Schematic representation of the primary structure of CNIH as in Figure 3D. The color-coded stars indicate the locations of the similarly labeled mutations in $\boldsymbol{B}$. Regions after the intracellular loop are omitted in this diagram. $\boldsymbol{B}$, We created alanine mutants spanning the regions that came up highly positive for AMPAR binding on the peptide arrays. Western blots showing CoIPs of GluA2 and CNIH-3 mutants coexpressed in HEK cells. Anti-HA antibody was used to pull down HA-tagged CNIH-1, CNIH-3, or CNIH-3 mutants. Inputs are shown on the top and CNIH-HA elutions on the bottom. The CNIH-3 mutants DEL32AAA, VPL104AAA, and LFY107AAA, labeled with color-coded stars, show reduced interaction with GluA2. C, A table summarizing the characteristics of the CNIH-3 alanine substitution mutations used in this study, including those shown in Figure $3 E$. These are listed by the residues and locations of the residues mutated. The second column lists whether or not they expressed and their ability to interact with GluA2 relative to WT CNIH-3. D, Top row, Single wavelength fluorescence microscopy images. Subcellular distribution of WT CNIH-3 and CNIH-3 mutants that showed decreased interaction in HEK cells. Total CNIH staining (green) was done using anti-HA antibody. Scale bar, $10 \mu \mathrm{m}$. The mutants show similar distributions in the cell to WT CNIH-3. Bottom row, Merged dual wavelength fluorescence microscopy images. CNIH-3HA surface staining (shown in green) of the cell lines indicated at the top of each column. Cells positive for CNIH-3 or CNIH-3 mutants are also mCherry positive because of the presence of IRES-mCherry in the plasmid (Note that, in the top row, only the green channel was recorded and thus mCherry signal is absent.) Scale bar, $10 \mu \mathrm{m}$. The mutants can all localize to the cell surface like WT CNIH-3, indicating that they are not mislocalized in the cell. $\boldsymbol{E}$, Sample traces from recordings obtained from outside-out patches from HEK cells coexpressing GluA2 and WT or mutant CNIH-3. The gray bar at the top indicates the duration of glutamate application. The traces were normalized to the peak, with the color-coded vertical scale bars indicating the original amplitude. $\boldsymbol{F}$, A bar graph summarizing the data ( \pm SEM) for the desensitization time constant $\left(\tau_{\text {des }}\right)$ of currents presented as sample traces in $E$. All datasets were compared by one-way ANOVA, followed by Sidak's multiple comparison test. * denotes statistical significance from no CNIH and \# from WT CNIH-3: ${ }^{* *}$ or ${ }^{\# \#} p<0.01,{ }^{* * *} p<0.001,{ }^{* * * *}$ or ${ }^{\# \# \#} p<0.0001$. For summary, see Table 1. 
Table 1. Summary of channel recordings

\begin{tabular}{lcr}
\hline & $t_{\text {des }} \pm$ SEM (ms) & $n$ \\
\hline No CNIH-3 & $4.76 \pm 0.16$ & 27 \\
CNIH-3 WT & $64.54 \pm 4.46$ & 11 \\
DEL32AAA & $28.28 \pm 1.17$ & 6 \\
VPL104AAA & $36.88 \pm 5.88$ & 5 \\
LFY107AAA & $44.48 \pm 1.68$ & 5 \\
CNIH-3del & $26.44 \pm 1.71$ & 8 \\
CNIH-3del2 & $46.51 \pm 6.95$ & 8 \\
CNIH-3delNTD & $35.91 \pm 4.91$ & 6 \\
CNIH-3del3 & $23.03 \pm 0.91$ & 6 \\
CNIH-3delLBD & $19.99 \pm 1.37$ & 6 \\
\hline
\end{tabular}

pressing GluA2 and $\mathrm{CNIH}-3$ was significantly reduced in the absence of NBQX $(p<0.001, n=8)$. Similar results were obtained from the cell line coexpressing GluA2 and stargazin $(p<$ $0.001, n=8$ ). Cells coexpressing GluA2 and CNIH-1 grew equally well regardless of the presence of NBQX. DOX was applied at the same concentration $(7.5 \mu \mathrm{g} / \mathrm{ml})$ in all experiments and did not affect the growth of any cell lines. We interpret that cell death and reduced cell proliferation are caused by the enhanced GluA2 ion channel activation by the glutamate present in the cell media. A weak functional interaction of CNIH-1 with AMPAR was seen in the channel recordings but not the cell proliferation assay because of assay sensitivity. Although both $\mathrm{CNIH}$ homologs $\mathrm{CNIH}-1$ and $\mathrm{CNIH}-3$ can physically interact with AMPARs in vitro (Fig. $5 A$ ), the magnitude of functional interaction with AMPARs was significantly different between the two homologs (Fig. 5G). This suggests that binding of CNIHs to AMPARs is dissociable from AMPAR channel modulation.

\section{Domains of GluA2 contributing to complex formation}

We next investigated which domain of AMPARs interacts with the loop region specific to $\mathrm{CNIH}-3$ using a peptide array containing peptides of the CNIH-1 and CNIH-3 extracellular loops and adjacent TM regions. Octa-histidine tagged GluA2 LBD (S1S2; Armstrong and Gouaux, 2000) or NTD (Jin et al., 2009; Rossmann et al., 2011) were used to probe the arrays (Fig. $6 A, D$ ). The LBD probe contains part of the linker that connects the LBD and TM4 (see Materials and Methods). Peptides binding to the AMPAR LBD or NTD were detected using an anti-His antibody, and the results (Fig. $6 B, E$, top) were analyzed using the same method as in Figure $3 D$ (shown in Fig. $6 C, F$ ). Residues that interacted with the probes are highlighted in either blue (CNIH-3) or red (CNIH-1). In a negative control experiment, we probed the array with only the anti-His antibody omitting the NTD or LBD probes and found only two positive spots (Fig. $6 E$, bottom). These spots were positive regardless of probing with NTD or LBD and thus removed from analysis. Because the two positive spots in the array probed with NTD were also positive in the negative control experiment, it is primarily the GluA2 LBD that interacts with the CNIH-3 extracellular loop. It is currently unclear whether the region encompassing the two spots also interacts with the NTD.

Membrane-proximal regions of $\mathrm{CNIH}-3$ were critical for the interaction with GluA2, and thus we inferred that, similarly, TMand membrane-proximal regions would be prime candidate regions within GluA2 responsible for the interaction. In light of the specificity of the interaction of CNIH-3 with the AMPAR subunit GluA2 but not with the kainate receptor subunit GluK2 (Fig. $5 E, F)$, we created a series of GluA2/GluK2 chimeric constructs that have varying degrees of conversion of the membrane- spanning segments and the linkers connecting the TMD and LBD (Fig. 6G,H). These chimeras are based on ones originally created and proven to be functional (Ayalon and Stern-Bach, 2001). When coexpressed in HEK cells, GluA2 interacts robustly with CNIH-3. In contrast, all of the GluA2/GluK2 chimeras showed a markedly decreased ability to interact with CNIH-3 $(p<0.0001$, ANOVA, $n=3$; Fig. $6 I$ ). Because there were no clear differences in the ability to interact with $\mathrm{CNIH}-3$ between the different chimeras (no statistical significance by ANOVA and Tukey's multiple comparisons test, $n=3$ ), these results did not identify a specific region in the membrane-proximal portion of GluA2 subunit that is critical for the CNIH interaction. However, they demonstrate that the maintenance of the intact GluA2 TM regions and membrane-proximal linkers is important for the interaction with CNIH-3. GluK2 did not coimmunoprecipitate with CNIH-3 from brain or HEK cells. However, this observation does not exclude the possibility that the biochemical conditions used, which favored AMPAR interaction with $\mathrm{CNIH}-3$, did not preserve kainate receptor interaction with $\mathrm{CNIH}-3$.

\section{CNIH-2/3-specific extracellular loop residues contribute to GluA2 interaction and gating}

The peptide array experiments in Figure 3 suggested an interaction between the extracellular loop region specific to CNIH-2/3 and AMPARs, but none of the alanine mutations within this specific region showed a significantly reduced interaction with GluA2. Additionally, the peptide array results in Figure 6 demonstrated that the AMPAR LBD interacts with the CNIH-3 extracellular loop, primarily in regions specific to $\mathrm{CNIH}-2 / 3$ and absent in CNIH-1/4. Because $\mathrm{CNIH}-2 / 3$ robustly modulate AMPAR function but CNIH-1/4 do not, the extracellular loop sequence selectively present in the active isoforms is of particular interest. Therefore, we designed a series of CNIH-3 mutants with targeted deletions within this $\mathrm{CNIH}-2 / 3$-specific loop. In $\mathrm{CNIH}$ 3 del, the entire portion was deleted. In CNIH-3del 2 the first half (residues PVHARERL) and in CNIH-3del3 the second half (residues RNIERICF) were deleted (Fig. 7A). These CNIH-3 mutants showed reduced interaction with GluA2 in CoIP experiments in HEK cells (Fig. 7 B, C). The full deletion and $\mathrm{CNIH}-3$ del3 resulted in a statistically significant reduction in interaction with AMPARs, suggesting that the $\mathrm{CNIH}-2 / 3$-specific region (especially the second half) is important for the interaction with AMPARs. However, this is likely a more intricate interaction that cannot be disrupted by simply mutating a few individual residues.

To further understand the interactions between the AMPAR extracellular domains and the CNIH-3 extracellular loop, we made targeted $\mathrm{CNIH}-3$ deletion mutants and removed the key residues that showed positive hits in the peptide array experiments: CNIH-3delNTD (residues HARERL deleted) and CNIH-3delLBD (residues ERICFLL deleted; Fig. 7A). In CoIP experiments, both the CNIH-3delLBD and CNIH-3delNTD mutants indeed showed a significantly reduced interaction with GluA2 compared with WT CNIH-3 (Fig. 7 B, C).

Comparison using one-way ANOVA followed by Tukey's multiple comparisons test revealed that deletions in the last half of the CNIH-2/3-specific region, including $\mathrm{CNIH}-3 \mathrm{del} 3$ and $\mathrm{CNIH}-3$ delLBD, results in the most significant reduction in interaction with GluA2 $\left({ }^{* *} p<0.01\right)$, whereas deletions in the first half, including CNIH-3del2 and CNIH-3delNTD, were not significant or had a less significant effect $\left({ }^{*} p<0.05\right)$. The same pattern was observed in our electrophysiological recordings: although all of these mutants slow GluA2 desensitization significantly less than the WT, this effect is more pronounced for 
A

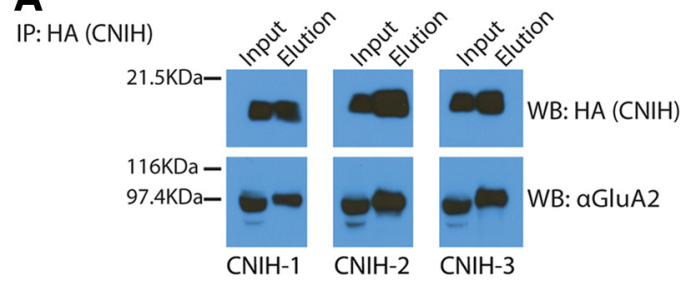

C R.YMSRPVMSGPGLYDPTTIMNADILAYCQK.E

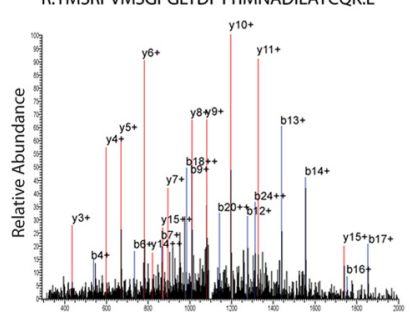

D

\begin{tabular}{|l|l|l|}
\hline HEK cell purification (peptide/spectrum counts) & GluA2 & GluN1/GluN2B \\
\hline GluA2 AMPA-R subunit & $210 / 5239$ & 0 \\
\hline GluN1 NMDA-R subunit & 0 & $72 / 316$ \\
\hline GluN2B NMDA-R subunit & 0 & $131 / 916$ \\
\hline CNIH-3 Cornichon 3 & $2 / 13$ & 0 \\
\hline CNIH-1 Cornichon 1 & $3 / 5$ & 0 \\
\hline CNIH-4 Cornichon 4 & $2 / 2$ & 0 \\
\hline
\end{tabular}

E

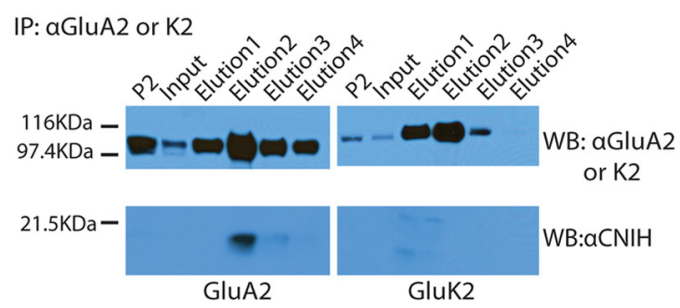

F

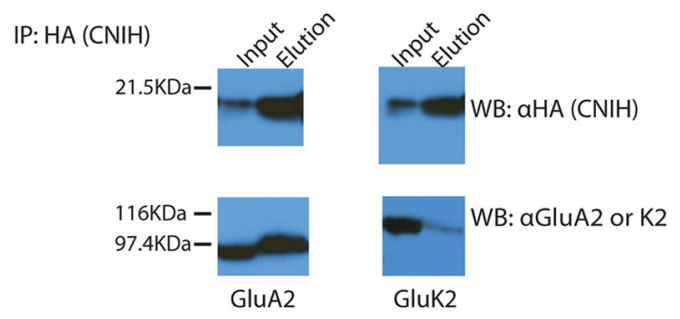

B
$\mathrm{CNIH}-2$

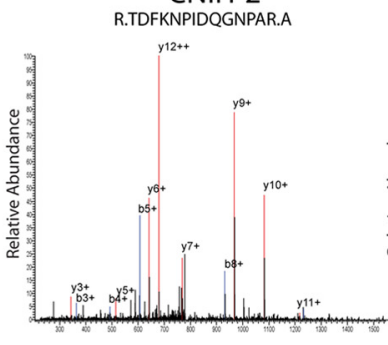

$\mathrm{m} / \mathrm{z}$

\begin{tabular}{|c|l|l|l|l|}
\hline Accession & Spec. count & Pep. count & \% AA & Description \\
\hline IPI00030882 & 106 & 630 & 67 & GluA2 Flop Isoform \\
\hline IPI00219216 & 105 & 624 & 66.5 & GluA2 Flip Isoform \\
\hline IPI00030649 & 2 & 2 & 20.1 & CNIH-1 \\
\hline IPI00335052 & 3 & 7 & 8.8 & CNIH-2 \\
\hline IPI00152192 & 2 & 3 & 7.5 & CNIH-3 \\
\hline IPI00000115 & 2 & 4 & 14.4 & CNIH-4 \\
\hline
\end{tabular}

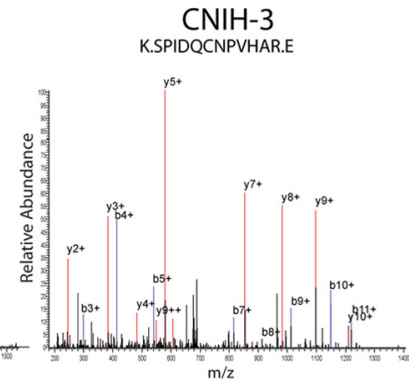

G

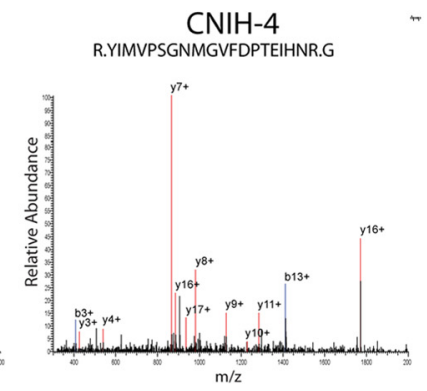

30 hours after induction
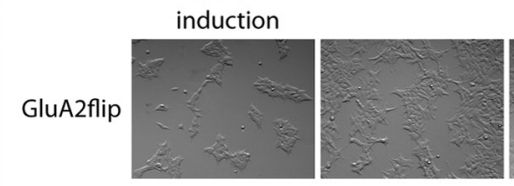

$+30 \mathrm{MMNBQX}$
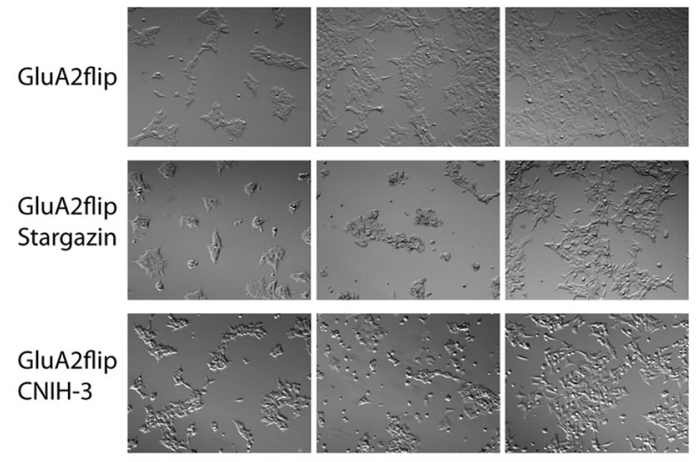

GluA2flip

CNIH-1 (\#1)
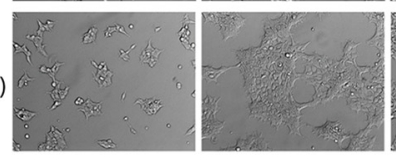

H

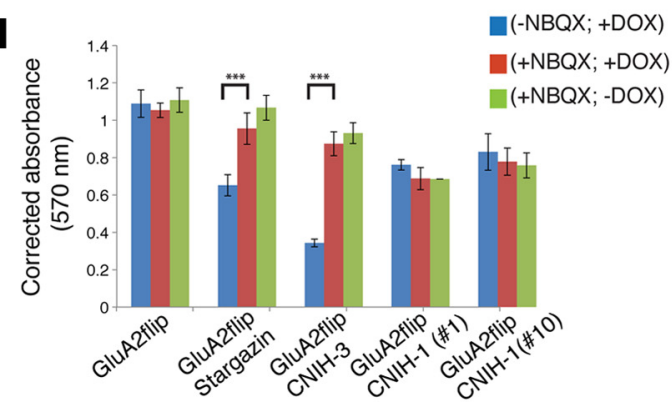

Figure 5. Specificity of interaction between AMPARs and CNIHs. A, HEK cell ColPs. HA-tagged CNIH-1, CNIH-2, or CNIH-3 were coexpressed with GluA2 and pulled down with the HA antibody. Western blots (WB) were probed with HA to recognize recombinant CNIHs and GluA2CT antibody. B, Native AMPAR complexes purified from human cortex with GluA2 antibodies analyzed by high-resolution MS. The table summarizes CNIH homologs that copurified with GluA2. The spectrum count (Spec), peptide count (Pep), and percentage coverage (\%AA) identified by liquid chromatography MS/MS are listed for each protein. C, GluA2 affinity purification followed by MS from human cortex identifies distinct peptides for CNIH-1, CNIH-2, CNIH-3, and CNIH-4. Shown are representative MS/MS spectra for each CNIH isoform. D, Endogenous proteins in HEK cells that interact with either overexpressed GluA2 or GluN1/GluN2B identified by MS. E, Western blots of GluA2 or GluK2 immunoprecipitated from adolescent rat brain probed with GluA2 or GluK2 and CNIH antibody (Hoshino et al., 2007) The P2 fractions, postdetergent-solubilized inputs, and four elutions are shown for each IP. F, HEK cell CoIPs. CNIH-3HA that was coexpressed with either GluA2 or GluK2 was pulled down with an HA antibody. Western blots were probed with anti-HA to recognize recombinant CNIH-3 and GluA2 or GluK2 antibodies. Detergent-solubilized inputs and CNIH-3HA pull-down elutions are depicted. G, Cell death assay of the GluA2-only parental cell line, GluA2/ stargazin, GluA2/CNIH-3HA, and GluA2/CNIH-1HA (\#1) cell lines. DIC images of HEK cells are provided before DOX induction of GluA2 and $30 \mathrm{~h}$ after induction in both the absence and presence of the competitive AMPAR antagonist NBQX. Scale bar, $200 \mu \mathrm{m}$. Coexpression of stargazin or CNIH-3 but not CNIH-1 (or nothing) with GluA2 leads to AMPAR-mediated cell death in the absence of the AMPAR antagonist NBQX, demonstrating that these AMPAR auxiliary subunits functionally modulate AMPARs in our HEK cell system. $\boldsymbol{H}$, Bar graph representing a summary of nonradioactive cell proliferation assay. The normalized quantity of formazan product correlates with cell proliferation and is represented by corrected absorbance at $570 \mathrm{~nm}$ is plotted in the vertical axis. Different cell lines tested are indicated in the horizontal axis. The following three conditions were tested: ( $-\mathrm{NBQX},+\mathrm{DOX})$ (blue), (+NBQX, +DOX) (red), and (+NBQX, $-\mathrm{DOX})$ (green). \#1 and \#10 indicates two independently isolated clones of the GluA2/CNIH-1 cell line. ${ }^{* *} p<0.001$; error bars indicate \pm SEM. 

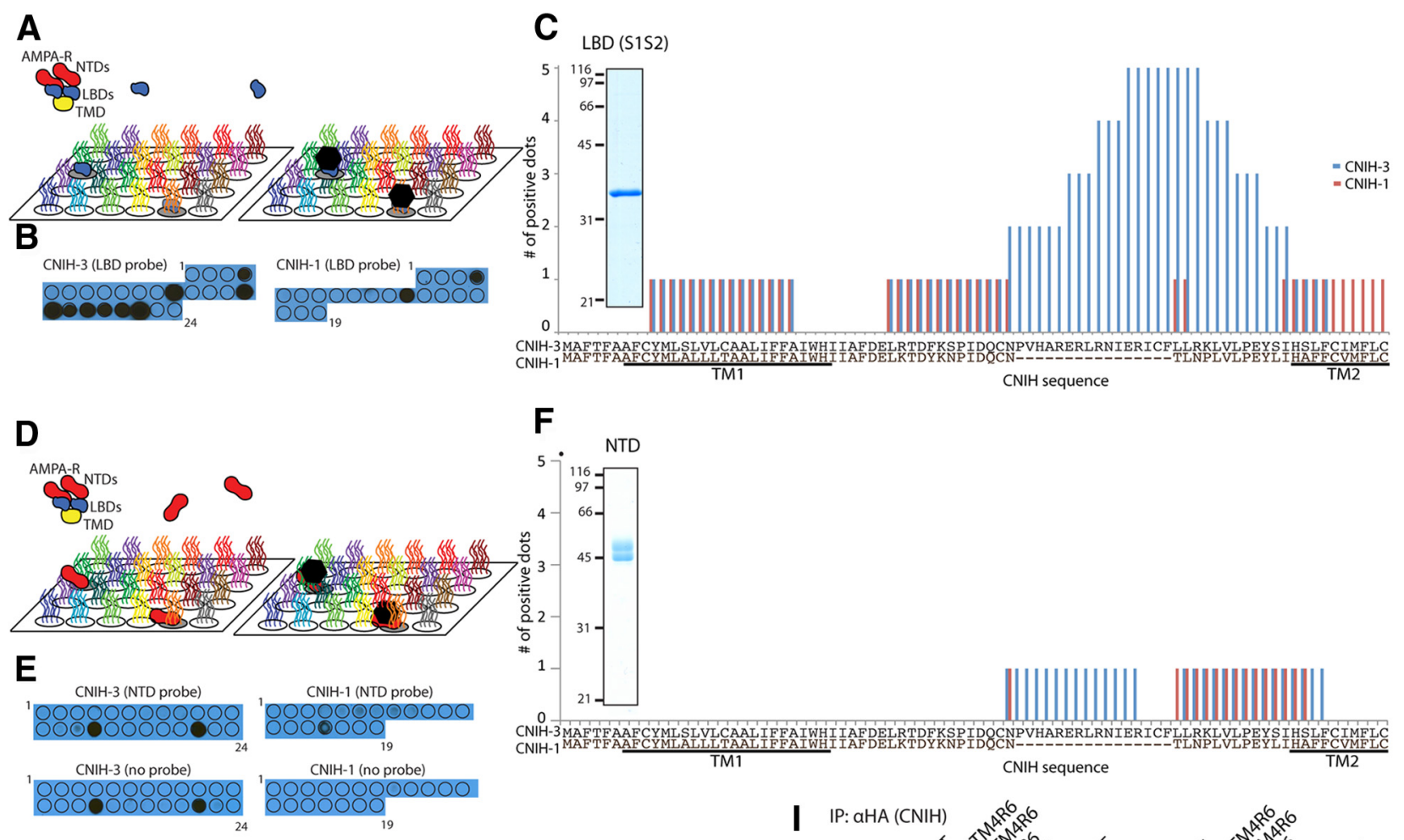

G

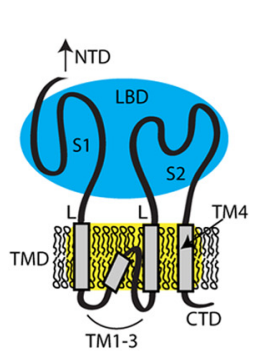

$\mathbf{H}$

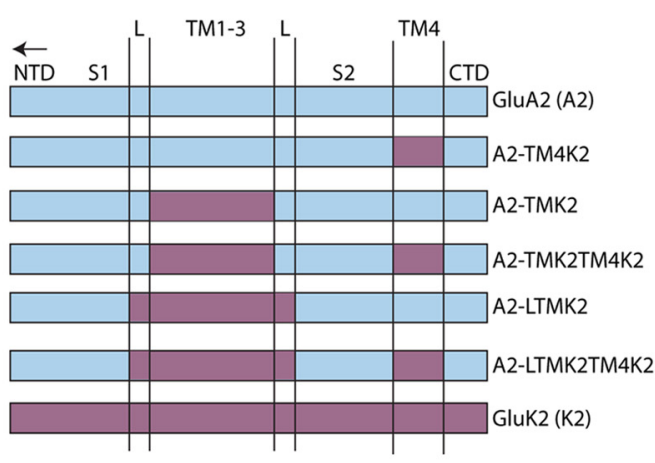

I IP: aHA (CNIH)
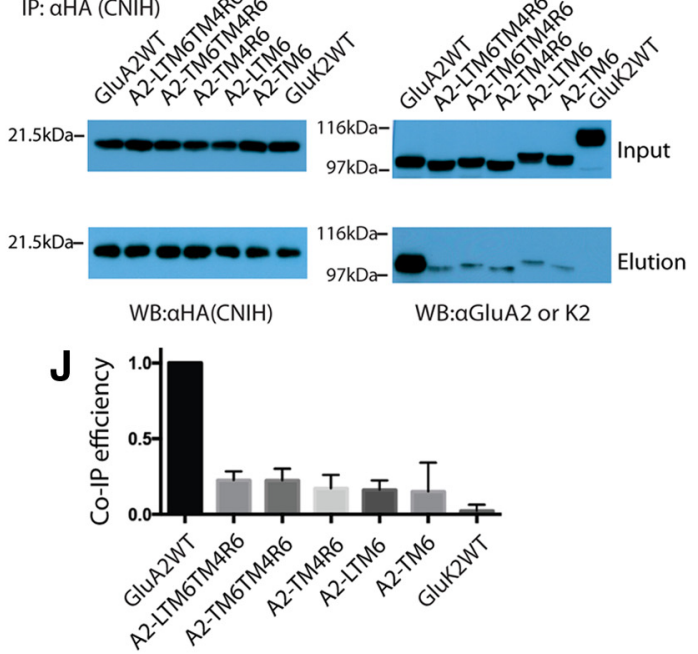

Figure 6. Interaction of isolated AMPAR domains with CNIH-3. A, Diagram of peptide array assay. Instead of full-length AMPAR protein, isolated AMPAR LBD (GluA2 S1S2) was incubated on peptide arrays. Western blotting was performed to determine to which peptides AMPAR LBDs were bound. $\boldsymbol{B}$, Western blot of peptide array probed with LBD, followed by HRP-conjugated anti-His antibody. A dot on each array represents 15 aa of the protein, and adjacent dots are shifted by 3 aa. Dots go from left to right to cover the whole CNIH-3 (from spot 1 to spot 24 ) and the CNIH-1 loop sequences (from spot 1 to spot 19). Blackened dots are positive for AMPAR binding. C, SDS-PAGE of the LBD probe stained with Coomassie Brilliant Blue shown in inset. Histogram representing the number of positive dots for each amino acid in the aligned protein sequence for CNIH-3 and CNIH-1 when GluA2 LBD was applied. D, Diagram of peptide array assay. Instead of full-length AMPAR protein, the isolated AMPAR NTD (GluA2 NTD) was incubated on peptide arrays. Western blotting was performed to determine to which peptides AMPARs bound. $E$, Top, Western blot of peptide array probed with NTD, followed by HRP-conjugated anti-His antibody. The order and the peptide sequence of each spot are identical to the arrays shown in $\boldsymbol{B}$. Blackened dots are positive for AMPAR binding. Bottom, Negative control Western blot of peptide array probed with only HRP-conjugated anti-His antibody. The peptide arrays shown are duplicate arrays containing identical set of peptides as above. $\boldsymbol{F}$, SDS-PAGE of the NTD probe stained with Coomassie Brilliant Blue shown in the inset. Histogram representing the number of positive dots for each amino acid in the aligned protein sequence for CNIH-3 and CNIH-1 when GluA2 NTD was applied. G, Diagram of glutamate receptor topology in which NTD is removed, and LBD and TMD are highlighted to facilitate understanding of the GluA2/GluK2 chimeras in $\boldsymbol{H}$. CTD, C-terminal domain. $\boldsymbol{H}$, Schematic showing GluA2/GluK2 chimeras in which the TMDs and linker (L) regions between the TMs and LBD are swapped to varying degrees. Portions in which the GluA2 sequence is preserved are represented in light blue, and regions in which the sequence is swapped to that of GluK2 are in purple. $I$, Western blots (WB) showing CoIPs of GluA2, GluK2, and chimeras with CNIH-3 mutants in HEK cells. Inputs are shown on the top and CNIH-HA elutions on bottom. All chimeras in which TM and linker portions are swapped to GluK2 show a reduced ability to interact with CNIH-3.J, A bar graph summarizing the quantification of ColP efficiency of constructs in $I$. There was a significant CoIP of WT GluA2 compared with the others $(p<0.0001, n=3)$. No significant difference in ColP efficiency was detected among the chimeras (error bars indicate \pm SEM).

CNIH-3del3 and CNIH-3delLBD than for CNIH-3del2 and CNIH-3delNTD (Fig. 7 D, E; Table 1).

Because the CNIH-2/3-specific segment is critical for gating modulation of AMPARs, we revisited whether three smaller alterations in this segment described previously that retain normal ability to interact with GluA2 (RER61AAA, LRN64AAA, and IER67AAA; Fig. $4 B$ ) affect desensitization kinetics differently from WT CNIH-3. Collectively, these mutants appeared to affect the rate of GluA2 desensitization to a smaller extent than the WT CNIH-3; however, this effect was only statistically significant in case of LRN64AAA (Fig. 7F). 
A

$\mathrm{CNIH}-2 / 3$ specific region

\begin{tabular}{|c|c|c|}
\hline CNIH-3 WT & \multicolumn{2}{|c|}{ QCNPVHARERLRNIERICFLLRK } \\
\hline CNIH-3 del & QCN & LLRK \\
\hline CNIH-3 del2 & QCN & RNIERICFLLRK \\
\hline $\mathrm{CNIH}-3$ del3 & QCNPVHARERL & LLRK \\
\hline CNIH-3 delNTD & QCNPV & LRNIERICFLLRK \\
\hline CNIH-3 delLBD & QCNPVHARERLRNI & R K \\
\hline
\end{tabular}

B

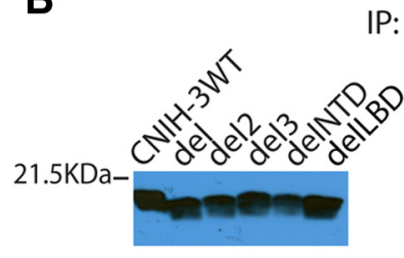

$21.5 \mathrm{KDa}-$

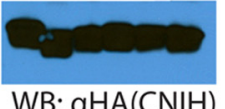

D

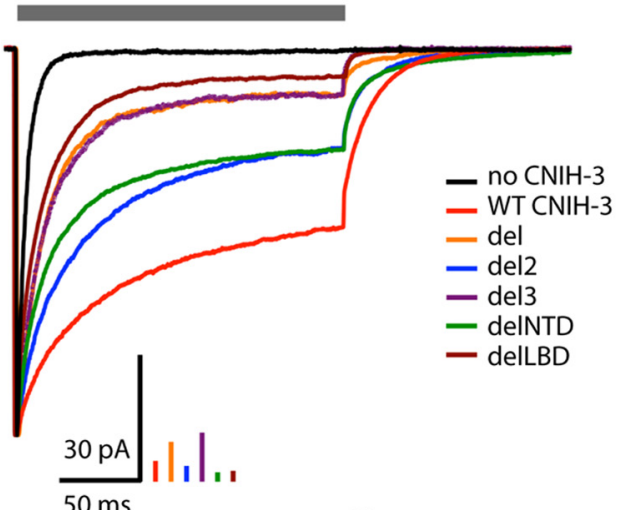

IP: HA (CNIH)

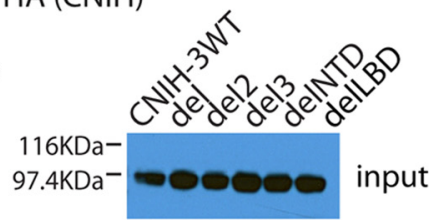

$116 \mathrm{KDa}-$ 97.4KDaWB: aGluA2
C

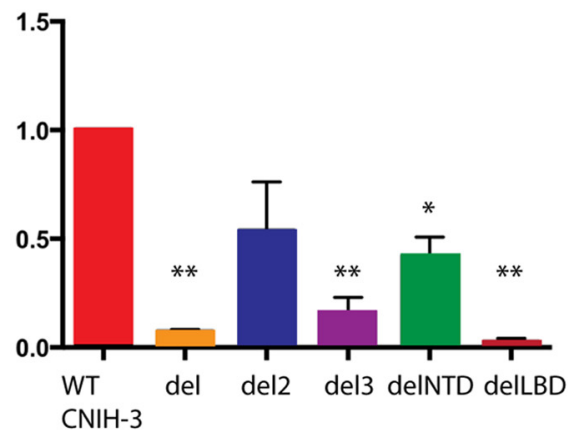

E

Elution

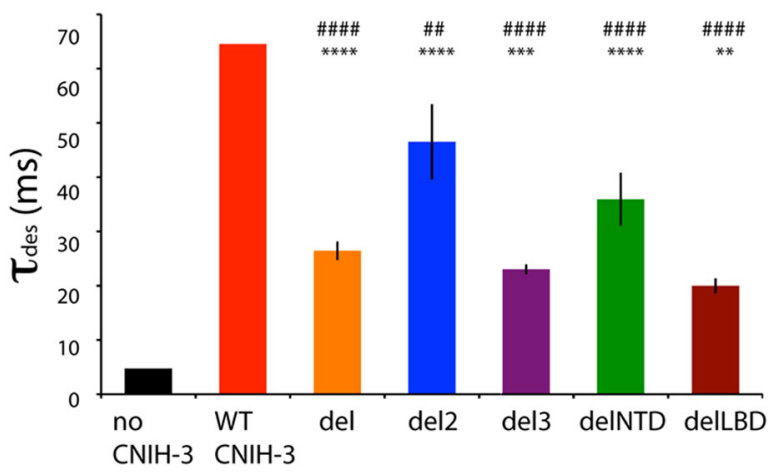

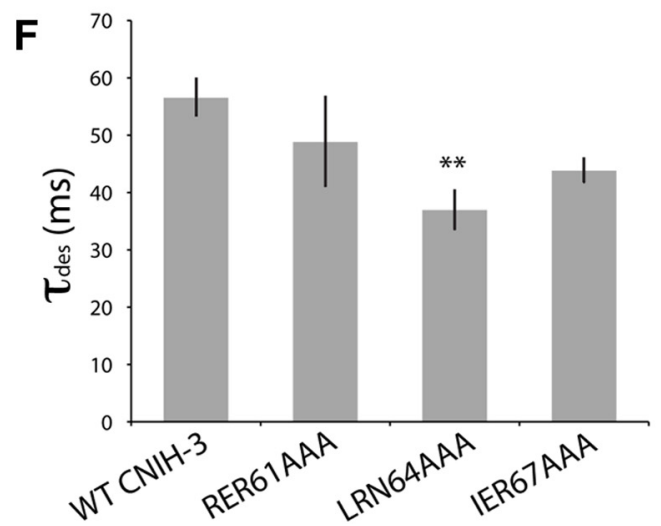

Figure 7. CNIH mutants show reduced physical and functional interaction with GluA2. $A$, Schematic showing the deletions made to CNIH-3. These deletions are based on the highest hit residues from the peptide array results. CNIH-3deINTD and CNIH-3delLBD are the mutants in which the hotspots identified for the NTD and LBD were deleted. B, Western blots (WB) showing ColPs of GluA2 and CNIH-3 mutants coexpressed in HEK cells. Inputs are shown on the top and CNIH-HA elutions on the bottom. Both CNIH-3 NTD and LBD deletion mutants show a reduced interaction with GluA2, although this is more pronounced for the $\mathrm{CNIH}-3$ del and del3 mutants. C, A bar graph summary of the quantification of two experimental replicates of data shown in $\boldsymbol{B}$. The vertical axis represents normalized efficiency of ColP such that the value of CNIH-3 WT is equal to $1\left(^{*} p<0.05,{ }^{* *} p<0.01, n=2\right.$, error bars indicate \pm SEM). $D$, Sample traces from recordings obtained from outside-out patches from HEK cells coexpressing GluA2 and WT or mutant CNIH-3. The gray bar at the top indicates the duration of glutamate application. The traces were normalized to the peak, with the color-coded vertical scale bars indicating the original amplitude. Experiments were done and analyzed together with those shown in Figure 4, Eand $F$, using a single one-way ANOVA test, followed by Sidak's multiple comparison test ( ${ }^{*}$ denotes statistical significance from no CNIH and \# from WT CNIH-3), and thus the positive and negative controls (no CNIH-3 and WT CNIH-3) are already presented in Figure 4 F but shown here again for convenience. We emphasize that we are not reusing the same control data for multiple tests. $\boldsymbol{E}$, A bar graph summarizing (Figure legend continues.) 
Together, these experiments show that the CNIH-2/3-specific region in the loop is responsible for the physical and functional interaction with AMPAR and that the AMPAR LBD primarily interacts within this region. Given the greater number of positive spots in the peptide array and the greater deficit in AMPAR desensitization and copurification in the targeted CNIH-3 mutants, the LBD likely plays a more significant role in this interaction than the NTD. The reduced gating modulation observed in the CNIH-3delNTD mutant may be a neighborhood effect attributable to mutating adjacent residues critical for the LBD interaction.

Interestingly, mutating a few amino acids in the CNIH-2/3specific loop segment (LRN64AAA) results in increased rate of desensitization compared with the WT CNIH-3 but maintains normal physical interaction. This demonstrates a proof of principle that it is possible to produce engineered $\mathrm{CNIH}-3$ s that possess altered gating modulation without affecting their physical interaction with AMPARs.

\section{Discussion}

The molecular mechanisms of AMPAR modulation by auxiliary subunits are best understood for the extensively studied TARPs (Chen et al., 2000; Tomita et al., 2005; Turetsky et al., 2005; Menuz et al., 2007) but are unclear for other auxiliary subunits, such as CNIHs. In this study, by combining a variety of techniques, including biochemistry, single-particle EM, proteomics, cell biology, electrophysiology, and high-throughput peptide arrays, we investigate the AMPAR/CNIH interaction and determine how specific CNIH amino acid residues interact physically and functionally with the AMPAR extracellular domains.

The functional interaction between TARPs and AMPARs requires the first extracellular loop and the C-terminal portions of the TARP molecule (Tomita et al., 2005). However, it is unclear whether or how these regions physically interact with the AMPAR itself. Specifically, they could be critical for transducing allosteric modulation without physically interacting with the extracellular portion of the AMPAR, with the actual binding occurring elsewhere in the molecule. Previously, there was no direct evidence for physical interaction between the extracellular domain of AMPARs and extracellular loops of any of the known auxiliary subunits.

To address these questions, we focused on CNIHs, because they are suitable for extensive structure-function correlation studies as a result of their low molecular weight. Screening by sensitive peptide array-based binding assays followed by sitedirected mutagenesis identified, at a precision of several amino acids, two loci within the extracellular loop of CNIH-3 that mediate physical interaction with GluA2 (Fig. 4A, left star and blue region). An additional locus that mediates binding exists in the

\section{$\leftarrow$}

(Figure legend continued.) the data ( \pm SEM) for the desensitization time constant $\left(\tau_{\text {des }}\right)$ of currents presented (examples) in $\boldsymbol{D}$. Experiments were done and analyzed together with those shown in Figure 4, $E$ and $F$, using a single one-way ANOVA test, followed by Sidak's multiple comparison test ${ }^{*}$ denotes statistical significance from no CNIH and \# from WT CNIH-3: ** or $\# p<0.01,{ }^{* * *} p<0.001,{ }^{* * * *}$ or $\left.{ }^{\# \# \#} p<0.0001\right)$, and thus the positive and negative controls (no CNIH-3 and WT CNIH-3) are the same as in Figure 4F, shown here again for convenience. For summary, see Table 1. $\boldsymbol{F}$, A bar graph summarizing the effect of three $\mathrm{CNIH}-3$ mutations (RER61AAA, LRN64AAA, and IER67AAA) described in Figure $4 B$ on GluA2 desensitization rate. Data were analyzed using a single one-way ANOVA test, followed by Sidak's multiple comparison test. ${ }^{* *}$ denotes statistical significance from WT CNIH-3 $(p=0.0045) ; \tau_{\text {des }}=$ $56.6 \pm 3.2(n=13), 48.8 \pm 7.9(n=7), 36.9 \pm 3.5(n=8)$, and $43.8 \pm 2.2(n=9)$ for WT, RER61AAA, LRN64AAA, and IER67AAA, respectively.
TM region and adjacent intracellular loop (Fig. $4 A$, right two stars). Furthermore, the extracellular LBD physically interacts with the CNIH-3 extracellular loop. AMPARs by themselves are blocked by their antagonist CNQX, but this antagonist induces gating when AMPARs are in complex with TARPs (Menuz et al., 2007). Based on the observation that the crystal structure of the LBD was no different whether in complex with CNQX or the full antagonist NBQX, it has been hypothesized that TARPs amplify the conformational changes of the LBD of AMPARs (Menuz et al., 2007). Despite this hypothesis, no direct binding between the LBD and the stargazin extracellular loop has been demonstrated to date. This study on CNIH-3 highlights the novel AMPAR LBD interaction involved in the auxiliary subunit-mediated modulation of AMPAR gating. Similar interactions likely apply to auxiliary subunits other than $\mathrm{CNIH}-3$, such as for stargazin/TARPs.

We find that CNIH-1 and CNIH-3 associate with GluA2, but gating modulation activity is significantly stronger in CNIH-3containing complexes, suggesting that binding and AMPAR gating modulation are dissociable mechanisms. Consistently, the two TM-proximal segments of CNIH-3 necessary for the physical interaction with AMPARs (Fig. $4 A, B$, green stars) are well conserved among the CNIHs. In contrast, the extracellular loop segment specific to $\mathrm{CNIH}-2 / 3$ is involved in the physical interaction and also in modulation of AMPARs (Fig. $4 A$, blue segment). The CNIH-3 LRN64AAA mutant, which binds normally to AMPARs but possesses attenuated gating modulation activity, represents an interesting case in which a small amino acid alteration results in a phenotype dissociating the ability to bind and to modulate gating.

We report that CNIH-1 interacts with AMPARs. What is the functional significance of CNIH-1 in the nervous system? Transcript levels of CNIH-1, CNIH-2, and CNIH-3 are all upregulated in the dorsolateral prefrontal cortex of brains from schizophrenic patients (Drummond et al., 2012), consistent with the idea that there may be functional significance of CNIH-1 in human brain. C. elegans have a CNIH homolog, CNI-1, that is more homologous to mammalian CNIH-1 than CNIH-2/3 (Brockie et al., 2013). The cni-1 mutant worm exhibits increased glutamategated currents and a dramatic hyperreversal behavioral phenotype, whereas overexpression of CNI-1 or vertebrate $\mathrm{CNIH}$ homologs lead to the opposite effect. These experiments demonstrate a conserved role for the $\mathrm{CNIH}$ homologs in limiting the ER export of AMPARs (Brockie et al., 2013). However, the CNIH loss-of-function phenotype observed in C. elegans differs from that observed in mice. In the mouse hippocampus, knock-out of CNIH-2/3 resulted in reduction of glutamate-evoked currents (Herring et al., 2013). In mice, CNIHs positively regulate AMPAR forward trafficking, whereas in C. elegans they negatively regulate this process. Our work suggests that CNIHs and AMPARs make physical contacts at multiple points, with two regions of CNIHs contributing to stabilizing the complex and a third region contributing to both channel modulation and complex stabilization. The former regions are conserved between all species, including C. elegans, and thus the evolutional acquisition of the third contact region in mammals may have contributed to the functional diversification. Additional studies will be required to clarify the precise regulatory roles of $\mathrm{CNIHs}$ in different species.

The size of the TM density of the AMPAR particle significantly increased when CNIH-3 was present. Additional Fab labeling experiments confirmed that this increase is attributable to the presence of CNIH-3. Although this method cannot be used quantitatively because the Fab fragment binding affinity does not al- 
ways allow stoichiometric binding, the data clearly demonstrate instances of two CNIH-3 molecules simultaneously binding to a single GluA2 tetramer. Even in the presence of CNIH-3 the two NTD dimers are close to each other and the structure resembles the previously reported domain organization of the extracellular domains of GluA2 tetramers in the unliganded state (Nakagawa et al., 2005, 2006).

From our data, it is unclear whether the AMPAR NTD is also involved in CNIH-3-mediated functional modulation of AMPARs (Figs. 6, 7). Binding sites for extracellular proteins within the NTD have been suggested for many glutamate receptor types, including neuronal pentraxins (O’Brien et al., 1999; Sia et al., 2007) and N-cadherin (Passafaro et al., 2003; Saglietti et al., 2007) for AMPARs, Cbln1 for delta-2 receptors (Matsuda et al., 2010), and ephrin receptors for NMDARs (Dalva et al., 2000). For AMPARs in particular, the NTD has been shown to play an important role in the regulation of receptor assembly by acting as a gatekeeper to ensure ionotropic GluR subtype-specific assembly (Leuschner and Hoch, 1999; Ayalon and Stern-Bach, 2001; Rossmann et al., 2011; Herguedas et al., 2013). Recent structural data and computational modeling suggest that NTDs of AMPARs are flexible enough to accommodate inter-protomer rotation, which could potentially be transduced to the downstream receptor components that mediate gating (Sukumaran et al., 2011; Dutta et al., 2012). However, given the crystal structure of claudin-15 (Suzuki et al., 2014), a distant homolog of stargazin/ TARPs, unless the NTD could move toward the membrane [which is suggested in the EM structure of AMPAR bound to glutamate (Nakagawa et al., 2005)] or the extracellular loops of auxiliary subunits adopt conformations distinct from claudin15 , it would be unlikely that the NTD could interact with the extracellular loops of the auxiliary subunits. Of note, an interaction between the NTD and TARPs has indeed been described (O. Cais and I. Greger, unpublished observations). Additional biophysical studies are needed to address this attractive hypothesis.

In conclusion, our detailed analysis of the interaction provides greater insight about the complexity of AMPAR modulation by auxiliary subunits. We mapped the interactions between the AMPAR and CNIH-3, confirming previous speculations about interactions between extracellular loops of auxiliary subunits with the AMPAR LBD. This knowledge will be useful in conducting higher-resolution structural studies of AMPAR complexes, which may pave the way to developing new therapeutic agents targeting AMPARs.

\section{References}

Armstrong N, Gouaux E (2000) Mechanisms for activation and antagonism of an AMPA-sensitive glutamate receptor: crystal structures of the GluR2 ligand binding core. Neuron 28:165-181. CrossRef Medline

Ayalon G, Stern-Bach Y (2001) Functional assembly of AMPA and kainate receptors is mediated by several discrete protein-protein interactions. Neuron 31:103-113. CrossRef Medline

Bern M, Goldberg D, McDonald WH, Yates JR 3rd (2004) Automatic quality assessment of peptide tandem mass spectra. Bioinformatics 20 Suppl 1:i49-54. CrossRef Medline

Boudkkazi S, Brechet A, Schwenk J, Fakler B (2014) Cornichon2 dictates the time course of excitatory transmission at individual hippocampal synapses. Neuron 82:848-858. CrossRef Medline

Brockie PJ, Jensen M, Mellem JE, Jensen E, Yamasaki T, Wang R, Maxfield D, Thacker C, Hoerndli F, Dunn PJ, Tomita S, Madsen DM, Maricq AV (2013) Cornichons control ER export of AMPA receptors to regulate synaptic excitability. Neuron 80:129-142. CrossRef Medline

Campling BG, Pym J, Galbraith PR, Cole SP (1988) Use of the MTT assay for rapid determination of chemosensitivity of human leukemic blast cells. Leuk Res 12:823-831. CrossRef Medline

Chen GQ, Sun Y, Jin R, Gouaux E (1998) Probing the ligand binding do- main of the GluR2 receptor by proteolysis and deletion mutagenesis defines domain boundaries and yields a crystallizable construct. Protein Sci 7:2623-2630. CrossRef Medline

Chen L, Chetkovich DM, Petralia RS, Sweeney NT, Kawasaki Y, Wenthold RJ, Bredt DS, Nicoll RA (2000) Stargazin regulates synaptic targeting of AMPA receptors by two distinct mechanisms. Nature 408:936-943. CrossRef Medline

Coombs ID, Soto D, Zonouzi M, Renzi M, Shelley C, Farrant M, Cull-Candy SG (2012) Cornichons modify channel properties of recombinant and glial AMPA receptors. J Neurosci 32:9796-9804. CrossRef Medline

Dalva MB, Takasu MA, Lin MZ, Shamah SM, Hu L, Gale NW, Greenberg ME (2000) EphB receptors interact with NMDA receptors and regulate excitatory synapse formation. Cell 103:945-956. CrossRef Medline

Drummond JB, Simmons M, Haroutunian V, Meador-Woodruff JH (2012) Upregulation of cornichon transcripts in the dorsolateral prefrontal cortex in schizophrenia. Neuroreport 23:1031-1034. CrossRef Medline

Dutta A, Shrivastava IH, Sukumaran M, Greger IH, Bahar I (2012) Comparative dynamics of NMDA- and AMPA-glutamate receptor N-terminal domains. Structure 20:1838-1849. CrossRef Medline

Eng J, McCormack A, Yates J (1994) An approach to correlate tandem mass spectral data of peptides with amino acid sequences in a protein database. J Am Soc Mass Spectrom 5:976-989. CrossRef Medline

Farina AN, Blain KY, Maruo T, Kwiatkowski W, Choe S, Nakagawa T (2011) Separation of domain contacts is required for heterotetrameric assembly of functional NMDA receptors. J Neurosci 31:3565-3579. CrossRef Medline

Frank J, Radermacher M, Penczek P, Zhu J, Li Y, Ladjadj M, Leith A (1996) SPIDER and WEB: processing and visualization of images in 3D electron microscopy and related fields. J Struct Biol 116:190-199. CrossRef Medline

Frank R (1995) Simultaneous and combinatorial chemical synthesis techniques for the generation and screening of molecular diversity. J Biotechnol 41:259-272. CrossRef Medline

Harmel N, Cokic B, Zolles G, Berkefeld H, Mauric V, Fakler B, Stein V, Klöcker N (2012) AMPA receptors commandeer an ancient cargo exporter for use as an auxiliary subunit for signaling. PLoS One 7:e30681. CrossRef Medline

Hashimoto K, Fukaya M, Qiao X, Sakimura K, Watanabe M, Kano M (1999) Impairment of AMPA receptor function in cerebellar granule cells of ataxic mutant mouse stargazer. J Neurosci 19:6027-6036. Medline

Herguedas B, Krieger J, Greger IH (2013) Receptor heteromeric assemblyhow it works and why it matters: the case of ionotropic glutamate receptors. Prog Mol Biol Transl Sci 117:361-386. CrossRef Medline

Herring BE, Shi Y, Suh YH, Zheng CY, Blankenship SM, Roche KW, Nicoll RA (2013) Cornichon proteins determine the subunit composition of synaptic AMPA receptors. Neuron 77:1083-1096. CrossRef Medline

Horning MS, Mayer ML (2004) Regulation of AMPA receptor gating by ligand binding core dimers. Neuron 41:379-388. CrossRef Medline

Hoshino H, Uchida T, Otsuki T, Kawamoto S, Okubo K, Takeichi M, Chisaka O (2007) Cornichon-like protein facilitates secretion of HB-EGF and regulates proper development of cranial nerves. Mol Biol Cell 18:11431152. CrossRef Medline

Jackson AC, Nicoll RA (2011) The expanding social network of ionotropic glutamate receptors: TARPs and other transmembrane auxiliary subunits. Neuron 70:178-199. CrossRef Medline

Jin R, Singh SK, Gu S, Furukawa H, Sobolevsky AI, Zhou J, Jin Y, Gouaux E (2009) Crystal structure and association behaviour of the GluR2 aminoterminal domain. EMBO J 28:1812-1823. CrossRef Medline

Jover R, Ponsoda X, Castell JV, Gómez-Lechón MJ (1994) Acute cytotoxicity of ten chemicals in human and rat cultured hepatocytes and in cell lines: correlation between in vitro data and human lethal concentrations. Toxicol In Vitro 8:47-54. CrossRef Medline

Kalashnikova E, Lorca RA, Kaur I, Barisone GA, Li B, Ishimaru T, Trimmer JS, Mohapatra DP, Díaz E (2010) SynDIG1: an activity-regulated, AMPA- receptor-interacting transmembrane protein that regulates excitatory synapse development. Neuron 65:80-93. CrossRef Medline

Kang MG, Nuriya M, Guo Y, Martindale KD, Lee DZ, Huganir RL (2012) Proteomic analysis of AMPA receptor complexes. J Biol Chem 287: 28632-28645. CrossRef Medline

Kato AS, Gill MB, Ho MT, Yu H, Tu Y, Siuda ER, Wang H, Qian YW, Nisenbaum ES, Tomita S, Bredt DS (2010) Hippocampal AMPA recep- 
tor gating controlled by both TARP and cornichon proteins. Neuron 68:1082-1096. CrossRef Medline

Leuschner WD, Hoch W (1999) Subtype-specific assembly of alpha-amino3-hydroxy-5-methyl-4-isoxazole propionic acid receptor subunits is mediated by their n-terminal domains. J Biol Chem 274:16907-16916. CrossRef Medline

MacCoss MJ, Wu CC, Yates JR 3rd (2002) Probability-based validation of protein identifications using a modified SEQUEST algorithm. Anal Chem 74:5593-5599. Medline

Matsuda K, Miura E, Miyazaki T, Kakegawa W, Emi K, Narumi S, Fukazawa Y, Ito-Ishida A, Kondo T, Shigemoto R, Watanabe M, Yuzaki M (2010) Cbln1 is a ligand for an orphan glutamate receptor delta2, a bidirectional synapse organizer. Science 328:363-368. CrossRef Medline

Menuz K, Stroud RM, Nicoll RA, Hays FA (2007) TARP auxiliary subunits switch AMPA receptor antagonists into partial agonists. Science 318:815817. CrossRef Medline

Mosmann T (1983) Rapid colorimetric assay for cellular growth and survival: application to proliferation and cytotoxicity assays. J Immunol Methods 65:55-63. CrossRef Medline

Nakagawa T, Cheng Y, Ramm E, Sheng M, Walz T (2005) Structure and different conformational states of native AMPA receptor complexes. $\mathrm{Na}-$ ture 433:545-549. CrossRef Medline

Nakagawa T, Cheng Y, Sheng M, Walz T (2006) Three-dimensional structure of an AMPA receptor without associated stargazin/TARP proteins. Biol Chem 387:179-187. CrossRef Medline

Nicoll RA, Tomita S, Bredt DS (2006) Auxiliary subunits assist AMPA-type glutamate receptors. Science 311:1253-1256. CrossRef Medline

O'Brien RJ, Xu D, Petralia RS, Steward O, Huganir RL, Worley P (1999) Synaptic clustering of AMPA receptors by the extracellular immediateearly gene product Narp. Neuron 23:309-323. CrossRef Medline

Ohi M, Li Y, Cheng Y, Walz T (2004) Negative staining and image classification-powerful tools in modern electron microscopy. Biol Proced Online 6:23-34. CrossRef Medline

Passafaro M, Nakagawa T, Sala C, Sheng M (2003) Induction of dendritic spines by an extracellular domain of AMPA receptor subunit GluR2. Nature 424:677-681. CrossRef Medline

Peng J, Elias JE, Thoreen CC, Licklider LJ, Gygi SP (2003) Evaluation of multidimensional chromatography coupled with tandem mass spectrometry (LC/LC-MS/MS) for large-scale protein analysis: the yeast proteome. J Proteome Res 2:43-50. Medline

Rossmann M, Sukumaran M, Penn AC, Veprintsev DB, Babu MM, Greger IH (2011) Subunit-selective N-terminal domain associations organize the formation of AMPA receptor heteromers. EMBO J 30:959-971. CrossRef Medline

Sadygov RG, Eng J, Durr E, Saraf A, McDonald H, MacCoss MJ, Yates JR, 3rd (2002) Code developments to improve the efficiency of automated MS/MS spectra interpretation. J Proteome Res 1:211-215. Medline

Saglietti L, Dequidt C, Kamieniarz K, Rousset MC, Valnegri P, Thoumine O, Beretta F, Fagni L, Choquet D, Sala C, Sheng M, Passafaro M (2007) Extracellular interactions between GluR2 and N-cadherin in spine regulation. Neuron 54:461-477. CrossRef Medline

Schwenk J, Harmel N, Zolles G, Bildl W, Kulik A, Heimrich B, Chisaka O, Jonas P, Schulte U, Fakler B, Klöcker N (2009) Functional proteomics identify cornichon proteins as auxiliary subunits of AMPA receptors. Science 323:1313-1319. CrossRef Medline

Schwenk J, Harmel N, Brechet A, Zolles G, Berkefeld H, Müller CS, Bildl W, Baehrens D, Hüber B, Kulik A, Klöcker N, Schulte U, Fakler B (2012) High-resolution proteomics unravel architecture and molecular diversity of native AMPA receptor complexes. Neuron 74:621-633. CrossRef Medline
Shanks NF, Maruo T, Farina AN, Ellisman MH, Nakagawa T (2010) Contribution of the global subunit structure and stargazin on the maturation of AMPA receptors. J Neurosci 30:2728-2740. CrossRef Medline

Shanks NF, Savas JN, Maruo T, Cais O, Hirao A, Oe S, Ghosh A, Noda Y, Greger IH, Yates JR 3rd, Nakagawa T (2012) Differences in AMPA and Kainate Receptor Interactomes Facilitate Identification of AMPA Receptor Auxiliary Subunit GSG1L. Cell Rep 1:590-598. CrossRef Medline

Sheng M, Cummings J, Roldan LA, Jan YN, Jan LY (1994) Changing subunit composition of heteromeric NMDA receptors during development of rat cortex. Nature 368:144-147. CrossRef Medline

Shi Y, Suh YH, Milstein AD, Isozaki K, Schmid SM, Roche KW, Nicoll RA (2010) Functional comparison of the effects of TARPs and cornichons on AMPA receptor trafficking and gating. Proc Natl Acad Sci U S A 107: 16315-16319. CrossRef Medline

Sia GM, Béïque JC, Rumbaugh G, Cho R, Worley PF, Huganir RL (2007) Interaction of the N-terminal domain of the AMPA receptor GluR4 subunit with the neuronal pentraxin NP1 mediates GluR4 synaptic recruitment. Neuron 55:87-102. CrossRef Medline

Sukumaran M, Rossmann M, Shrivastava I, Dutta A, Bahar I, Greger IH (2011) Dynamics and allosteric potential of the AMPA receptor $\mathrm{N}$-terminal domain. EMBO J 30:972-982. CrossRef Medline

Sun Y, Olson R, Horning M, Armstrong N, Mayer M, Gouaux E (2002) Mechanism of glutamate receptor desensitization. Nature 417:245-253. CrossRef Medline

Suzuki H, Nishizawa T, Tani K, Yamazaki Y, Tamura A, Ishitani R, Dohmae N, Tsukita S, Nureki O, Fujiyoshi Y (2014) Crystal structure of a claudin provides insight into the architecture of tight junctions. Science 344:304307. CrossRef Medline

Tabb DL, McDonald WH, Yates JR, 3rd (2002) DTASelect and Contrast: tools for assembling and comparing protein identifications from shotgun proteomics. J Proteome Res 1:21-26. Medline

Tomita S, Adesnik H, Sekiguchi M, Zhang W, Wada K, Howe JR, Nicoll RA, Bredt DS (2005) Stargazin modulates AMPA receptor gating and trafficking by distinct domains. Nature 435:1052-1058. CrossRef Medline

Turetsky D, Garringer E, Patneau DK (2005) Stargazin modulates native AMPA receptor functional properties by two distinct mechanisms. J Neurosci 25:7438-7448. CrossRef Medline

Vandenberghe W, Nicoll RA, Bredt DS (2005) Stargazin is an AMPA receptor auxiliary subunit. Proc Natl Acad Sci U S A 102:485-490. CrossRef Medline

von Engelhardt J, Mack V, Sprengel R, Kavenstock N, Li KW, Stern-Bach Y, Smit AB, Seeburg PH, Monyer H (2010) CKAMP44: a brain-specific protein attenuating short-term synaptic plasticity in the dentate gyrus. Science 327:1518-1522. CrossRef Medline

Wang R, Walker CS, Brockie PJ, Francis MM, Mellem JE, Madsen DM, Maricq AV (2008) Evolutionary conserved role for TARPs in the gating of glutamate receptors and tuning of synaptic function. Neuron 59:9971008. CrossRef Medline

Wang R, Mellem JE, Jensen M, Brockie PJ, Walker CS, Hoerndli FJ, Hauth L, Madsen DM, Maricq AV (2012) The SOL-2/Neto auxiliary protein modulates the function of AMPA-subtype ionotropic glutamate receptors. Neuron 75:838-850. CrossRef Medline

Washburn MP, Wolters D, Yates JR, 3rd (2001) Large-scale analysis of the yeast proteome by multidimensional protein identification technology. Nat Biotechnol 19:242-247. CrossRef Medline

Zheng Y, Mellem JE, Brockie PJ, Madsen DM, Maricq AV (2004) SOL-1 is a CUB-domain protein required for GLR-1 glutamate receptor function in C. elegans. Nature 427:451-457. CrossRef Medline 